\title{
PRÊMIO DE RISCO E A POLÍTICA MONETÁRIA NO BRASIL
}

\author{
Rogério LÚcio Silva Junior * \\ José Angelo Divino ${ }^{\dagger}$
}

\begin{abstract}
Resumo
Esse artigo aplicou o modelo DSGE desenvolvido por Christiano et al. (2010) aos dados da economia brasileira no período recente, visando analisar a relação entre política monetária e o prêmio de risco de mercado. Esse modelo foi escolhido porque incorpora o setor financeiro e empréstimos bancários a empresas a uma estrutura novo keynesiana com rigidez de preços e salários. Os resultados indicam que o prêmio de risco e os choques no investimento possuem relevância para explicar os ciclos econômicos no Brasil. O prêmio de risco é um canal de transmissão para a política monetária via mercado de crédito. Constatou-se, também, que o Banco Central reagiu em desacordo com as recomendações usuais de política no episódio da recente crise financeira global.
\end{abstract}

Palavras-chave: Modelo DSGE; Estimação Bayesiana; Fricções Financeiras; Flutuações Econômicas; Mercado de Crédito.

\begin{abstract}
This paper applied the DSGE model developed by Christiano et al. (2010) to the Brazilian data in the recent period in order to analyze the relationship between monetary policy and market risk premium. This model was chosen because it incorporates the financial sector and bank loans to entrepreneurs into a new keynesian framework with sticky prices and wages. The results indicate that the risk premium and investment shocks are relevant to explain the business cycle in Brazil. The risk premium is a transmission channel for the monetary policy through the credit market. It was also found that the Central Bank reacted in disagreement with the usual policy recommendations in the episode of the recent global financial crisis.
\end{abstract}

Keywords: DSGE Model; Bayesian Estimation; Financial Frictions; Economic Fluctuations; Credit Market.

JEL classification: E22, E44, E51, E52, E58

\footnotetext{
* Universidade Católica de Brasília, Programa de Pós-Graduação em Economia.

E-mail: rogerioj@ucb.br

† Universidade Católica de Brasília, Programa de Pós-Graduação em Economia.

E-mail: jangelo@pos.ucb.br
} 


\section{Introdução}

Após a adoção do Plano Real, em 1994, a economia brasileira experimentou redução considerável na elevada inflação da década anterior. No início do Plano, porém, as taxa de juros eram muito altas, dificultando o desenvolvimento do mercado de crédito. Com o passar do tempo, o controle inflacionário e a redução das taxas de juros possibilitaram a expansão do mercado de crédito para consumo e para a produção de bens e serviços. O crédito empresarial, contudo, depende da rentabilidade e do risco da atividade empreendedora e os bancos procuram considerar esses fatores na análise de risco para a concessão de empréstimos.

Na literatura nacional, alguns trabalhos analisaram a relação entre crédito, nível de atividade econômica e inflação. Zerbini \& Fabiana (2002), por exemplo, investigam os efeitos da inflação sobre o crédito em um ambiente de múltiplas quebras estruturais. Para o período de 1970 a 1998, em que o país enfrentou diversos planos de estabilização, eles encontraram uma relação inversa entre crédito ao setor privado e inflação. Isso sugere que a estabilidade de preços contribui para a expansão do mercado de crédito.

Souza-Sobrinho (2003) fornece evidências de que o canal do crédito é um mecanismo de transmissão da política monetária. A modelagem econométrica aplicada revelou que aumentos na taxa de juros da política monetária afetam os juros bancários e reduzem a oferta de crédito. Além disso, ele encontrou evidências de casualidade temporal entre oferta de crédito, spread bancário e produto.

A Tabela 1 reporta coeficientes de correlação simples entre as variáveis trimestrais crédito ao setor privado, spread de crédito, produto e inflação no período de 1995:1 a 2010:4. Os valores obtidos estão de acordo com os fatos estilizados encontrados na literatura. Há uma correlação positiva entre crédito e produto, e uma negativa entre crédito e inflação, em conformidade com Zerbini \& Fabiana (2002) e Souza-Sobrinho (2003). Por outro lado, a correlação entre crédito e spread, apesar de negativa, não se mostrou relevante, com coeficiente estimado muito próximo de zero. As correlações entre spread e produto, e entre spread e inflação também se situaram próximas de zero, embora com valores positivos. Dessa forma, conforme já evidenciado por outros estudos, o crédito é correlacionado com o ciclo econômico brasileiro.

Tabela 1: Matriz de correlação

\begin{tabular}{lrrrr}
\hline Produto & 1,000 & & & \\
Inflação & $-0,380$ & 1,000 & & \\
Spread & 0,200 & 0,080 & 1,000 & \\
Crédito & 0,690 & $-0,300$ & $-0,070$ & 1,000 \\
\hline \multicolumn{5}{l}{ Fonte: Elaboração própria. }
\end{tabular}

O objetivo desse artigo é aplicar, ao Brasil, um modelo de Equilíbrio Geral Dinâmico Estocástico (DSGE) para avaliar os impactos de choques no risco das atividades empresariais, na política monetária e no investimento, bem como suas interações, sobre o ciclo econômico brasileiro. ${ }^{1}$ O modelo DSGE

\footnotetext{
${ }^{1}$ Uma discussão sobre a importância relativa desses choques pode ser encontrada em Araújo (2012), Kanczuk (2004), Souza-Sobrinho (2011) e Nolan \& Thoenissen (2009), por exemplo.
} 
utilizado segue o arcabouço teórico proposto por Christiano et al. (2010). O principal intuito é analisar como interagem a política monetária com o risco de mercado e suas implicações para a dinâmica macroeconômica. O modelo possui um mercado de crédito e imperfeições advindas de fricção financeira ao estilo do acelerador financeiro de Bernanke et al. (1996). A importância do setor financeiro para a economia ficou evidente com a recente crise econômica internacional, que teve sua origem justamente naquele setor da economia americana. O modelo desenvolvido por Christiano et al. (2010) foi escolhido porque inclui o setor financeiro, segundo Bernanke et al. (1999), ${ }^{2}$ na abordagem DSGE padrão ao estilo Christiano et al. (2005).

Uma das principais contribuições do modelo de Christiano et al. (2010) foi mostrar que o risco de mercado, isto é, a intensidade do choque no retorno dos empreendimentos, aumenta o spread do crédito para as empresas e amplia o ciclo econômico. Para chegar a essa evidência, foi conduzida uma estimação bayesiana do modelo teórico utilizando dados dos Estados Unidos e da União Europeia. Os resultados apontaram que o aumento no risco dos empreendimentos financiados é um dos responsáveis pelas flutuações no produto daquelas economias.

O modelo básico, devido a Christiano et al. (2010), refere-se a um modelo DSGE que estende o trabalho seminal de Christiano et al. (2005). O ambiente da economia artificial é bastante rico, incorporando vários tipos de rigidez nominais. Com isso, após um choque positivo na política monetária, logrou sucesso em gerar uma resposta da inflação com elevada persistência e uma resposta hump-shaped do produto.

Além disso, gerou respostas hump-shaped no investimento, consumo, emprego, lucros e produtividade, e uma resposta pequena nos salários reais. Finalmente, a taxa de juros e a taxa de crescimento da moeda movem-se em direções opostas depois de um choque na política monetária. Assim, a economia artificial conseguiu replicar com precisão a dinâmica das séries observadas nos Estados Unidos e União Européia.

O modelo incorpora rigidez nominal nos salários e preços. A rigidez nos salários nominais baseia-se em Erceg et al. (2000) e é crucial para o desempenho empírico. A rigidez nos preços, que segue a estrutura de Calvo (1983), tem um papel secundário. Dados os papéis da rigidez de preços e salários, os autores sugerem que esses aspectos sejam modelados de forma estrutural e integrada num arcabouço DSGE.

A fricção financeira segue a estrutura do acelerador financeiro de Bernanke et al. (1996), em que há um modelo de gerações superpostas que incorpora uma relação negativa entre riqueza líquida dos devedores e a extensão dos empréstimos. Argumentam que, em períodos de recessão, a riqueza líquida dos que tomam emprestado tende a cair, por causa de menores vendas e lucros, e a necessidade de empréstimos tende a aumentar para financiar capital de giro ou custear os estoques não desejáveis.

Os emprestadores, porém, incorrem num custo de agência, isto é, o contrato de dívida padrão não incorpora a presença de informação assimétrica entre o emprestador e o tomador do empréstimo. Fundamentado em Townsend (1979), esse contrato de dívida na presença de informação assimétrica

\footnotetext{
${ }^{2}$ Em Bernanke et al. (1999) é apresentada a estrutura de acelerador financeiro de Bernanke et al. (1996) em uma modelagem Novo Keynesiana.
} 
fornece uma relação inversa entre a taxa de juros externa à empresa e a riqueza líquida da empresa.

Desse modo, quando a economia entra numa recessão, a riqueza líquida das empresas tende a cair e a taxa de juros de fundos externos tende a subir, diminuindo mais ainda as possibilidades de a empresa tomar emprestado. $\mathrm{O}$ resultado é a diminuição do nível de atividade da firma para um valor inferior ao obtido caso esta tivesse acesso ao empréstimo sem custos de agência.

A estimação do modelo de Christiano et al. (2010) por meio de técnicas bayesianas seguiu uma formulação similar ao estudo pioneiro de Smets \& Wouters (2003), que desenvolveram e estimaram um modelo DSGE com preços e salários rígidos para a zona do euro. O modelo incorpora vários elementos importantes, como formação de hábito, custo de ajustamento na acumulação de capital e a variável utilização da capacidade. O modelo é estimado com a aplicação de técnicas bayesianas, usando variáveis macroeconômicas observadas representadas por PIB, consumo, investimento, preços, salários reais, emprego e taxa de juros nominais. Além disso, foram introduzidos outros choques estruturais ortogonais, incluindo choque de produtividade, oferta de trabalho, investimento, preferências, custos de oferta e política monetária. Isso permitiu avaliar empiricamente os efeitos desses choques e suas contribuições aos ciclos dos negócios na zona do euro.

Outros autores, como Christensen \& Dib (2008) e De Graeve (2008), também desenvolveram e estimaram modelos DSGE com friç̧ões financeiras para a economia americana. Christensen \& Dib (2008) apresentam um modelo DSGE com preços rígidos e uma estrutura de acelerador financeiro proposta por Bernanke et al. (1999). O modelo foi estimado com e sem a inclusão do acelerador financeiro pelo método de máxima verossimilhança. Os testes baseados na capacidade preditiva rejeitam o modelo sem o acelerador financeiro, indicando que o modelo completo se ajustou melhor aos dados da economia americana.

No caso brasileiro, alguns estudos buscaram estimar modelos DSGE usando técnicas bayesianas. Sin \& Gaglianone (2006), por exemplo, estimam o modelo proposto por Smets \& Wouters (2007), que tem Christiano et al. (2005) como referência básica, mas não encontram um bom ajuste para as distribuições posteriores de alguns parâmetros. Análises de política monetária para uma economia aberta usando o arcabouço DSGE estão presentes em Silveira (2006), Silveira (2008) e Furlani et al. (2010). A interação entre as políticas monetária e fiscal é o foco principal de Nunes \& Portugal (2009) e Valli \& Carvalho (2010). Já Carvalho \& Valli (2011) analisam os impactos macroeconômicos decorrentes do uso de diferentes instrumentos de política fiscal em um modelo DSGE de economia aberta com agentes não Ricardianos. Uma mudança na dimensão da modelagem é proposta por De Castro et al. (2011), que desenvolvem um modelo DSGE de larga escala para analisar os efeitos de políticas econômicas alternativas e realizar previsões fora da amostra.

Esses modelos DSGE estimados para a economia brasileira, porém, não consideram o setor financeiro na estrutura teórica. Até mesmo o modelo De Castro et al. (2011) possui características de modelos DSGE tradicionais, como rigidez de preços e salários e custos de ajustamento. Para adequar o modelo à economia brasileira o autor inclui, também, uma autoridade fiscal que segue uma meta para superávit primário, preços administrados, financiamento externo para as importações e bens importados como insumos na função de produção. Apesar de construir uma economia artificial rica, não 
há incorporações de fricções financeiras. A inclusão do setor financeiro na modelagem pode contribuir para melhorar o ajuste do modelo aos dados, conforme notou De Graeve (2008). Dessa forma, uma contribuição deste artigo é estimar um modelo DSGE com fricção financeira para o Brasil.

Outra contribuição é evidenciar, empiricamente, a importância que o risco de mercado das atividades empresariais tem para o ciclo de negócios. A reconstrução dos choques na política monetária e no risco de mercado a partir do modelo estimado fornecem esse resultado. No período eleitoral de 2002 e na crise financeira global de 2008-2009, o risco das atividades empresariais teve elevação significativa. Esse aumento foi acompanhado por aumento no mark-up de preços no primeiro evento e por redução no segundo. Houve, também, mudança substancial na eficiência marginal do investimento, principalmente durante a crise financeira global. O Banco Central reagiu de acordo com as recomendações usuais de política, que sugerem afrouxamento monetário em períodos de aumento e restrição monetária quando ocorrem quedas no markup, somente no primeiro evento.

Conforme as simulações do modelo estimado com os dados da economia brasileira, a reação da autoridade monetária afeta diretamente o prêmio de risco das atividades empresariais, trazendo consequências para o mercado de crédito. Esse, por sua vez, tem efeitos sobre o consumo, investimento, produto e inflação. Desse modo, o prêmio de risco e o mercado de crédito constituem um relevante canal de transmissão para a política monetária.

Identificou-se, também, uma relação entre o risco de mercado e o ciclo econômico. Isso ocorre porque o volume e o spread de crédito às pessoas jurídicas dependem do risco de mercado da economia. Nesse cenário, a autoridade monetária possui um importante papel na mitigação do risco de mercado e consequente estabilização da economia.

O artigo está organizado em cinco seções. A próxima seção apresenta o modelo teórico com as equações que caracterizam o comportamento dos produtores de bens e de capital, dos empreendedores, dos bancos, das famílias, e do governo via políticas fiscal e monetária. A seção 3 descreve o método de estimação econométrica bayesiana. A seção 4 reporta e discute os resultados obtidos. Por fim, a quinta seção apresenta as considerações finais.

\section{Modelo Teórico}

Apresenta-se, a seguir, uma breve descrição do modelo de Christiano et al. (2010), que é composto por famílias, firmas, produtores de capital, empreendedores e bancos. No começo do período, as famílias ofertam trabalho e os empreendedores ofertam capital num mercado de fatores homogêneo. A família, também, divide seu saldo monetário entre moeda e depósito bancário. Moeda não paga juros, mas é mantida por gerar serviços de transação. Depósitos bancários, por outro lado, rendem juros. O banco empresta aos empreendedores para a provisão de finanças externas. As firmas usam trabalho e capital para produzir bens na economia.

O produto das firmas é convertido em bens de consumo, bens de investimento, bens usados na utilização da capacidade e no monitoramento bancário. Os produtores de capital combinam bens de investimento com capital comprado dos empreendedores para produzir novo capital. Esse novo capital é, então, adquirido pelos empreendedores, que fazem suas compras usando seus 
próprios recursos - riqueza líquida, ou patrimônio, que obtêm compondo os rendimentos de sua atividade período a período - e empréstimos bancários.

\subsection{Produção de Bens Finais}

O produto final, $Y_{t}$, é produzido por uma firma representativa, perfeitamente competitiva, com a seguinte tecnologia:

$$
Y_{t}=\left[\int_{0}^{1} Y_{j t}^{\frac{1}{\lambda_{f}}} d j\right]^{\lambda_{f}}, 1 \leq \lambda_{f}<\infty
$$

em que $Y_{j t}$ denota o insumo do bem intermediário $j$ no tempo $t$ e $\lambda_{f}$ é um parâmetro, com $j \in(0,1)$. $P_{t}$ e $P_{j t}$ denotam o preço corrente de $Y_{t}$ e $Y_{j t}$, respectivamente. A firma escolhe $Y_{j t}$ e $Y_{t}$ para maximizar lucros, tomando os preços como dados.

Assuma que o processo de avanço tecnológico contínuo na produção de bens de investimento faça o custo de produzir uma unidade de equipamento, medido em termos de unidade de consumo, declinar à taxa $\left(\Upsilon^{t} \mu_{\Upsilon, t}\right)$, onde $\Upsilon>1$ é a taxa de mudança tecnológica investimento específico, e $\mu_{\Upsilon, t}$ é um processo estocástico estacionário, que se refere ao preço relativo do choque de investimento. Como as firmas que produzem bens de consumo e bens de investimento usando produtos finais são assumidas como perfeitamente competitivas, os preços de equilíbrio na data $t$ dos bens de consumo e dos bens de investimento serão $P_{t}$ e $\frac{P_{t}}{\left(\mu_{\Upsilon, t} \Upsilon^{t}\right)}$, respectivamente.

$\mathrm{O}$ bem intermediário $j^{\text {th }}$ usado em 1 é produzido por um monopolista usando a seguinte função de produção:

$$
Y_{j t}= \begin{cases}\epsilon_{t} K_{j t}^{\alpha}\left(z_{t} l_{j t}\right)^{1-\alpha}-\Phi z_{t}^{*} & \text { se } \epsilon_{t} K_{j t}^{\alpha}\left(z_{t} l_{j t}\right)^{1-\alpha}>\Phi z_{t}^{*} \\ 0 & \text { caso contrário }\end{cases}
$$

onde $K_{j t}$ e $l_{j t}$ denotam serviços de capital e trabalho homogêneo, o escalar não negativo, $\Phi$, parametriza custos fixos de produção, $\epsilon_{t}$ é um choque estacionário na tecnologia e $z_{t}$ representa um componente persistente da tecnologia, que possui a seguinte representação de séries de tempo:

$$
z_{t}=\mu_{z, t} z_{t-1}
$$

em que $\mu_{z, t}$ é um processo estocástico estacionário. Devido ao processo tecnológico incorporado, a taxa de crescimento do produto é determinada pela seguinte condição:

$$
z_{t}^{*}=z_{t} \Upsilon^{\left(\frac{\alpha}{1-\alpha} t\right)}, \Upsilon>1
$$

que também motiva a escolha considerando a estrutura de custos fixos da firma em 3, $\Phi z_{t}^{*}$, e assegura que o estado estacionário não estocástico da economia exiba uma trajetória de crescimento equilibrado.

As firmas são competitivas nos mercados de fatores onde enfrentam uma taxa nominal de aluguel, $P \tilde{r}_{t}^{k}$, nos serviços de capital e uma taxa de salário nominal, $W_{t}$, nos serviços de trabalho.

Como resultado, o custo marginal real de se produzir uma unidade de produto $Y_{j t}$ é: 


$$
s_{t}=\left(\frac{1}{1-\alpha}\right)^{(1-\alpha)}\left(\frac{1}{\alpha}\right)^{\alpha}\left(\frac{\left(\tilde{r}_{t}^{k}\right)^{\alpha} \frac{W_{t}}{P_{t}}}{\epsilon_{t} z_{t}}\right)^{1-\alpha}
$$

Como, em equilíbrio, os custos marginais reais devem ser iguais aos custos de se reter uma unidade de capital dividido pelo produto marginal do capital, a taxa de aluguel satisfaz a seguinte condição:

$$
\tilde{r}_{t}^{k}=\frac{\alpha}{1-\alpha}\left(\frac{l_{j t}}{K_{j t}}\right)\left(\frac{W_{t}}{P_{t}}\right)
$$

O trabalho homogêneo empregado pelas firmas em 2 e o trabalho diferenciado ofertado pelas famílias individuais são relacionados da seguinte forma:

$$
l_{t}=\left[\int_{0}^{1}\left(h_{t, j}\right)^{\frac{1}{\lambda_{w}}} d j\right]^{\lambda_{w}}, 1 \leq \lambda_{w}
$$

em que a determinação de $h_{t, j}$ será discutida mais adiante.

Para ajustar preços, as firmas seguem uma variante do modelo de preços rígidos de Calvo (1983). Em cada período $t$, uma fração de firmas intermediárias, $1-\xi_{p}$, pode otimizar o seu preço. Se a $i_{t h}$ firma em $t$ não pode otimizar, então ela escolhe o preço de acordo com:

$$
P_{i t}=\tilde{\pi}_{t} P_{i, t-1}
$$

onde

$$
\tilde{\pi}_{t}=\left(\pi_{t}^{\text {target }}\right)^{\iota}\left(\pi_{t-1}\right)^{1-\iota}
$$

$\operatorname{com} \pi_{t-1}=\frac{P_{t-1}}{P_{t-2}}$ e $\pi_{t}^{\text {target }}$ sendo a meta de inflação da autoridade monetária. O parâmetro $l$ é o peso da meta de inflação nos preços. A $i^{\text {th }}$ firma que pode otimizar seu preço no tempo $t$ escolhe $P_{i, t}=\tilde{P}_{t}$ para maximizar os lucros descontados.

\subsection{Produtores de Capital}

Assume-se que haja um único produtor representativo de capital que atua competitivamente. No fim do período $t$, esse produtor compra equipamentos recém-produzidos a um preço unitário corrente de $P_{t}\left(\Upsilon^{t} \mu_{\Upsilon_{\Upsilon, t}}\right)^{-1}$, em termos de unidade de consumo que declina a taxa $\left(\Upsilon^{t} \mu_{\Upsilon, t}\right)$, e uma fração não depreciada de capital físico, $x$, que tem sido usada durante o ciclo de produção do período corrente. Capital velho e bens de investimento são combinados para produzir novo capital instalado, $x^{\prime}$, usando a seguinte tecnologia:

$$
x^{\prime}=x+F\left(I_{t}, I_{t-1}, \zeta_{i, t}\right)=x+\left[1-S\left(\frac{\zeta_{i, t} I_{t}}{I_{t-1}}\right)\right] I_{t}
$$

A tecnologia para transformar novo investimento em insumo de capital pronto para produção, $F(\bullet)$, envolve custos de instalação, $S\left(\frac{\zeta_{i, t} I_{t}}{I_{t-1}}\right)$, que aumentam de acordo com a taxa de crescimento do investimento. Permite-se uma variação estocástica exógena da função custo de investimento. Assim, 
um $\zeta_{i, t}$ positivo define um distúrbio negativo na eficiência marginal do investimento, que aumenta os custos de instalação. Seguindo Christiano et al. (2005), a função $S$ é restringida para satisfazer a seguinte propriedade $S^{\prime \prime}>0$.

Desde que a taxa marginal de transformação do capital instalado previamente (líquido de depreciação) seja unitária, o preço de capital novo e usado são os mesmos, denotados por $Q_{\bar{K}^{\prime}, t}$. Os lucros da firma no tempo $t$ são:

$$
\Pi_{t}^{k}=Q_{\bar{K}^{\prime}, t}\left\{x+\left[1-S\left(\frac{\zeta_{i, t} I_{t}}{I_{t-1}}\right)\right] I_{t}\right\}-Q_{\bar{K}^{\prime}, t} x-\frac{P_{t}}{\Upsilon^{t} \mu_{\Upsilon, t}} I_{t}
$$

O produtor de capital resolve:

$$
\max _{\left\{I_{t+j}, x_{t+j}\right\}} E_{t}\left\{\sum_{j=0}^{\infty} \beta^{j} \lambda_{t+j} \Pi_{t+j}^{k}\right\}
$$

em que $E_{t}$ é uma expectativa condicional ao conjunto de informação no tempo $t$, que inclui todos os choques do tempo $t$. Também, $\lambda_{t}$ é um multiplicador da restrição orçamentária das famílias. Deixe $\bar{K}_{t+j}$ denotar o estoque de capital do início do período $t+j$ na economia, e deixe $\delta$ ser a taxa de depreciação. Do problema do produtor de capital é evidente que qualquer valor de $x$ é maximizador de lucros. Então, fixando $x=(1-\delta) \bar{K}_{t+j}$ é consistente com maximização de lucros e equilíbrio de mercado.

Substituindo $x$ em 10, a equação resultante em 11, e resolvendo o problema dinâmico do produtor de capital, conduz à seguinte condição de otimalidade vinculando o preço do capital instalado $Q_{\bar{K}^{\prime}, t}$ ao preço dos bens de investimento, $\frac{P_{t}}{\Upsilon^{t} \mu_{\Upsilon, t}}$ :

$$
E_{t}\left[\lambda_{t} Q_{\bar{K}, t} F_{1, t}-\lambda \frac{P_{t}}{\Upsilon^{t} \mu_{\Upsilon, t}}+\beta \lambda_{t+1} Q_{\bar{K}, t+1} F_{2, t+1}\right]=0
$$

Em 12, $F_{i, t}$ denota a derivada da tecnologia de transformação, $F\left(I_{t}, I_{t-1}\right.$, $\left.\zeta_{i, t}\right)$, com respeito ao argumento $i$. O estoque de capital físico agregado, $\bar{K}_{t+1}$, evolui do seguinte modo:

$$
\bar{K}_{t+1}=(1-\delta) \bar{K}_{t}+F\left(I_{t}, I_{t-1}, \zeta_{i, t}\right)=(1-\delta) \bar{K}_{t}+\left[1-S\left(\frac{\zeta_{i, t} I_{t}}{I_{t-1}}\right)\right] I_{t}
$$

em que o estoque de capital de um período é determinado pelo que vem do período anterior $(1-\delta) \bar{K}_{t}$ líquido da taxa depreciação $(\delta)$ mais o investimento realizado. O investimento está sujeito a custos de instalação segundo a função $S$ que é convexa no crescimento do investimento.

\subsection{Empreendedores}

Há um grande número de empreendedores. O estado de um empreendedor, ao final do período $t$, é dado pelo seu nível de riqueza líquida, $N_{t+1}$. No mercado de bens, ao final do período $t$, o empreendedor combina sua riqueza líquida com um empréstimo bancário para adquirir novo capital físico instalado, $\bar{K}_{t+1}$, do produtor de capital. O empreendedor recebe experiência de um choque idiossincrático, $\omega$. O capital comprado, $\bar{K}_{t+1}$, é transformado em $\bar{K}_{t+1} \omega$, onde $\omega$ é uma variável aleatória normalmente distribuída entre todos os empreendedores, com função de distribuição acumulada denotada por 
$F_{t}(\omega)$. A hipótese sobre $\omega$ implica que os investimentos dos empreendedores são arriscados. A média e o desvio padrão de $\log \omega$ são $\mu_{\bar{\omega}}$ e $\sigma_{t}$, respectivamente. O parâmetro, $\mu_{\bar{\omega}}$, é fixado de modo que $E(\omega)=1$ quando $\sigma_{t}$ assume seu valor de estado estacionário. O desvio padrão, $\sigma_{t}$, é uma realização de um processo estocástico, referido abaixo como "choque de risco". Esse choque captura a ideia de que os riscos dos empreendedores variam no tempo. A variável aleatória, $\omega$, é observada pelo empreendedor, mas só pode ser observada pelo banco se este pagar um custo de monitoramento.

Depois de observar os choques do período $t+1$, o empreendedor determina a taxa de utilização do capital, $u_{t+1}$, e então aluga serviços de capital no mercado competitivo. A taxa de aluguel de uma unidade de serviços de capital, em unidades monetárias, é denotada por $\bar{r}_{t+1}^{k} P_{t+1}$. Escolhendo a taxa de utilização, cada empreendedor leva em conta a função custo:

$$
P_{t+1} \Upsilon^{-(t+1)} \tau_{t \mid+1}^{o i l} a\left(u_{t+1}\right) \omega \bar{K}_{t+1}
$$

Na especificação de Christiano et al. (2010), mais energia é consumida à medida que o capital é usado mais intensamente. Na análise empírica, $\tau_{t+1}^{o i l}$ é tratado como um processo exógeno, que é identificado como preço real do petróleo. Assume-se que $u=1, a(1)=0 a^{\prime}(u)=r^{k} a^{\prime \prime}(u)=\sigma_{a} r^{k}$, onde $r^{k}$ é o valor de estado estacionário da taxa de aluguel do capital. Então, $\frac{a^{\prime \prime}(u)}{a^{\prime}(u)}=\sigma_{a} \geq 0$ é um parâmetro que controla o grau de convexidade dos custos.

Depois de determinar a taxa de utilização do capital e receber o aluguel (líquido dos custos de transação), o empreendedor vende a fração não depreciada, $1-\delta$, de seu capital ao preço $Q_{\bar{K}, t+1}$ para o produtor de capital. $O$ pay-off total no período $t+1$ recebido pelo empreendedor com produtividade idiossincrática, $\omega$, expressa em termos de unidade monetárias, é dado por:

$$
\left\{\left[u_{t+1} \tilde{r}_{t+1}^{k}-\Upsilon^{-(t+1)} \tau_{t+1}^{o i l} a\left(u_{t+1}\right)\right] P_{t+1}+(1-\delta) Q_{\bar{K}, t+1}\right\} \omega \bar{K}_{t+1}
$$

É conveniente, conforme Christiano et al. (2010), expressar essa equação como:

$$
\left(1+R_{t+1}^{k}\right) Q_{\bar{K}, t} \omega \bar{K}_{t+1}
$$

em que $1+R_{t+1}^{k}$ é a taxa de juros média nominal bruta de retorno do capital para os empreendedores em $t+1$ :

$$
1+R_{t+1}^{k} \equiv \frac{\left\{\left[u_{t+1} \tilde{r}_{t+1}^{k}-\Upsilon^{-(t+1)} \tau_{t+1}^{o i l} a\left(u_{t+1}\right)\right] P_{t+1}+(1-\delta) Q_{\bar{K}, t+1}\right\}}{Q_{\bar{K}, t}}
$$

onde $\tau^{k}$ é uma alíquota de imposto constante sobre o capital. Como em Bernanke et al. (1999), os empreendedores podem autofinanciar somente uma fração do estoque de capital. Eles precisam de recursos externos na forma de empréstimos bancários. O contrato de dívida padrão que podem assumir antevêm que empreendedores com $\omega$ acima de um valor de corte endogenamente determinado, $\bar{\omega}_{t+1}$, pagam juros brutos, $Z_{t+1}$, em seus empréstimos bancários. O corte é definido pela seguinte expressão:

$$
\bar{\omega}_{t+1}\left(1+R_{t+1}^{k}\right) Q_{\bar{K}, t} \bar{K}_{t+1}=Z_{t+1} B_{t}
$$


onde $B_{t+1}=Q_{\bar{K}, t} \bar{K}_{t+1}-N_{t+1}$ é o empréstimo recebido do banco. Empreendedores com $\omega<\bar{\omega}_{t+1}$ não podem pagar totalmente seus empréstimos bancários. Empreendedores falidos devem vender seus ativos, $\left(1+R_{t+1}^{k}\right) \omega Q_{\bar{K}^{\prime}, t} \bar{K}_{t+1}<$ $Z_{t+1} B_{t+1}$, para o banco. Nesse caso, o banco deve monitorar o empreendedor ao custo $\mu\left(1+R_{t+1}^{k}\right) \omega Q_{\bar{K}^{\prime}, t} \bar{K}_{t+1}$ e reter o valor de liquidação dos ativos do empreendedor $(1-\mu)\left(1+R_{t+1}^{k}\right) \omega Q_{\bar{K}^{\prime}, t} \bar{K}_{t+1}$. O custo de monitoramento é proporcional à receita bruta dos empreendedores. A taxa de juros, $Z_{t+1}$, e a quantia de empréstimos são determinadas no contrato de dívida padrão. Os detalhes da intermediação financeira serão apresentados na próxima seção.

Depois que os empreendedores acordaram seu contrato de dívida com os bancos no período $t+1$ e o capital foi revendido para os produtores de capital, a riqueza dos empreendedores no período $t+1$ é determinada. Nesse ponto, empreendedores saem da economia com probabilidade $1-\gamma_{t+1}$ e sobrevivem com probabilidade $\gamma_{t+1}$. Uma fração $\Theta$ da riqueza líquida total dos empreendedores que fecham seus negócios é consumida na saída, e a fração restante da riqueza líquida é transferida como um pagamento lump-sum para as famílias. A probabilidade $\gamma_{t+1}$ é uma realização de um processo estocástico. A cada período, novos empreendedores entram em número suficiente para que a população permaneça constante. Novos empreendedores entrando no período $t+1$ recebem uma transferência inicial de riqueza líquida, $W^{e}$. Por $W^{e}$ ser relativamente pequeno, este processo de entrada e saída ajuda a assegurar que empreendedores não acumulem riqueza líquida suficiente para escapar das fricções financeiras.

A lei de movimento da riqueza líquida ponderada dos empreendedores, $\bar{N}_{t+1}$, é:

$$
\bar{N}_{t+1}=\gamma_{t}\left\{\begin{array}{l}
\left(1+R_{t}^{k}\right) Q_{\bar{K}^{\prime}, t-1} \bar{K}_{t}- \\
{\left[1+R_{t}^{e}+\frac{\mu \int_{0}^{\omega_{t}} \omega d F(\omega)\left(1+R_{t}^{k}\right) Q_{\bar{K}^{\prime}, t-1} \bar{K}_{t}}{Q_{\bar{K}^{\prime}, t-1} \bar{K}_{t}-\bar{N}_{t}}\right] *\left(Q_{\bar{K}^{\prime}, t-1} \bar{K}_{t}-\bar{N}_{t}\right)}
\end{array}\right\}+W^{e}
$$

onde $Q_{\bar{K}^{\prime}, t-1} \bar{K}_{t}-\bar{N}_{t}=B_{t}$. O objeto entre chaves em 19 representa o total de receitas dos empreendedores ativos no período $t$ menos o total de pagamentos para os bancos. Já o objeto entre colchetes representa os pagamentos médios dos empreendedores para os bancos, por unidade de moeda emprestada. Note que, se $F_{t}(\omega)$ varia no tempo e está sujeita a choques de risco, então, o prêmio de risco será:

$$
P_{t}^{e}=\mu\left[\frac{\int_{0}^{\bar{\omega}_{t}} \omega d F_{t}(\omega)\left(1+R_{t}^{k}\right) Q_{\bar{K}^{\prime}, t-1} \bar{K}_{t}}{Q_{\bar{K}^{\prime}, t-1} \bar{K}_{t}-\bar{N}_{t}}\right]
$$

Essa equação é a razão entre o volume de recursos dos empreendedores que faliram, líquido dos custos de monitoramento $\mu$, e o valor total dos empréstimos concedidos $Q_{\bar{K}^{\prime}, t-1} \bar{K}_{t}-\bar{N}_{t}$. Desse modo, quanto maior o montante monitorado pelo banco devido à falência em relação aos empréstimos concedidos maior será o prêmio de risco.

Note, também, que o valor da riqueza líquida dos empreendedores no período $t$ em 19 é perturbada por dois choques com diferentes estruturas temporais. O choque $\gamma_{t}$, chamado "choque financeiro de riqueza", é realizado no tempo $t$ e tem uma impacto na riqueza líquida contemporânea, $\bar{N}_{t+1}$. O choque de risco que diminui o lucro do empreendedor e a riqueza líquida ao final 
do período $t, \bar{N}_{t+1}$, é realizado ao final do período anterior, $\sigma_{t-1}$. No fim do período $t+1$, depois que a entrada e saída ocorreram, todos os empreendedores possuem um nível específico de riqueza líquida. O processo, então, continua por outros períodos no futuro.

\subsection{Bancos}

Christiano et al. (2010) assumiram que há um banco competitivo representativo, que tem características de sistema financeiro em que as transações ocorrem através dos mercados de títulos em vez da tradicional relação bancária. Os ativos do banco são os empréstimos para firmas e as obrigações são os depósitos bancários de propriedade das famílias.

O banco financia o setor empreendedor concedendo empréstimos. Esses empréstimos são concedidos no fim do período $t$ e pagos no fim de $t+1$. Nesse caso, o tempo do empréstimo corresponde ao tempo para o empréstimo maturar e o payoff originado pelo estoque de capital ocorrer. Há um setor no banco responsável por fazer os empréstimos aos empreendedores. No período $t, \mathrm{o}$ setor recebe $B_{t+1}$ de seu banco. As regras internas comprometem os administradores de empréstimos para os empreendedores pagarem ao banco uma taxa de juros nominal não contingente ao estado, $R_{t+1}^{e}$, no tempo $t+1$. Consequentemente, a quantia de crédito ofertada para os empreendedores no fim do tempo $t, B_{t+1}$, a taxa de juros, $R_{t+1}^{e}$, e a taxa de juros aplicada a esses empréstimos, $Z_{t+1}$, precisam maximizar a riqueza líquida do empreendedor ao final do contrato de empréstimo, sujeito a uma condição de lucro zero para o setor bancário:

$$
\left\{\begin{array}{l}
{\left[1-F_{t}\left(\bar{\omega}_{t+1}\right)\right] Z_{t+1} B_{t+1}+} \\
(1-\mu) \int_{0}^{\bar{\omega}_{t+1}} \omega d F_{t}(\omega)\left(1+R_{t+1}^{k}\right) Q_{\bar{K}^{\prime}, t} \bar{K}_{k+1}
\end{array}\right\}=\left(1+R_{t+1}^{e}\right) B_{t+1}
$$

O termo do lado direito da igualdade é a quantidade de fundos que o setor deve pagar para a instituição no fim do período $t+1$. Isso é uma quantidade conhecida no período $t$. Assume-se que $R_{t+1}^{e}$ seja não contingente aos choques em $t+1$. O primeiro termo na expressão do lado esquerdo da igualdade é o número de empreendedores que não faliram, $1-F_{t}\left(\bar{w}_{t+1}\right)$, multiplicado pelos juros e o pagamento do principal. O segundo termo corresponde aos fundos recebidos pelo banco dos empreendedores que faliram, líquido dos custos de monitoramento. Multiplique essa expressão por $\frac{\left(1+R_{t+1}^{e}\right)}{N_{t+1}}$ e leve em conta a definição de $\bar{\omega}_{t+1}$, para obter:

$$
\left[\Gamma_{t}\left(\bar{\omega}_{t+1}\right)-\mu G_{t}\left(\bar{\omega}_{t+1}\right)\right] \frac{1+R_{t+1}^{k}}{1+R_{t+1}^{e}}\left(B_{t+1}+N_{t+1}\right)=B_{t+1}
$$

onde

$$
\begin{gathered}
\Gamma_{t}\left(\bar{\omega}_{t+1}\right) \equiv \bar{\omega}_{t+1}\left[1-F_{t}\left(\bar{\omega}_{t+1}\right)\right]+G_{t}\left(\bar{\omega}_{t+1}\right) \\
G_{t}\left(\bar{\omega}_{t+1}\right) \equiv \int_{0}^{\bar{\omega}_{t+1}} \omega d F_{t}(\omega)
\end{gathered}
$$

Aqui, $\Gamma_{t}\left(\bar{\omega}_{t+1}\right)$ é a parcela do ganho dos empreendedores, $\left(1+R_{t+1}^{k}\right) Q_{\bar{K}^{\prime}, t}$ $\bar{K}_{k+1}$, recebido pela subsidiária bancária antes do custo de monitoramento. $\mathrm{O}$ 
termo $\Gamma_{t}\left(\bar{\omega}_{t+1}\right)-\mu G_{t}\left(\bar{\omega}_{t+1}\right)$ é a parcela líquida de custos de monitoramento. Também, $1-\Gamma_{t}\left(\bar{\omega}_{t+1}\right)$ denota a parcela dos ganhos brutos retidos pelos empreendedores. O contrato de dívida padrão tem dois parâmetros, $B_{t+1}$, e uma taxa de juros sem default, $Z_{T+1}$, (ou, equivalentemente, $\bar{\omega}_{t+1}$ ). As duas variáveis são escolhidas para maximizar o nível de riqueza líquida do empreendedor ao final do contrato sujeito à condição de lucro zero da subsidiária bancária:

$$
\max _{B_{t+1}, \bar{\omega}_{t+1}} E_{t}\left\{\begin{array}{l}
{\left[1-\Gamma_{t}\left(\bar{\omega}_{t+1}\right)\right] \frac{1+R_{t+1}^{k}}{1+R_{t+1}^{e}}\left(B_{t+1}+N_{t+1}\right)+} \\
\left.\eta_{t+1}\left(\left[\Gamma_{t}\left(\bar{\omega}_{t+1}\right)-\mu G_{t}\left(\bar{\omega}_{t+1}\right)\right] \frac{1+R_{t+1}^{k}}{1+R_{t+1}^{e}}\left(B_{t+1}+N_{t+1}\right)-B_{t+1}\right)\right)
\end{array}\right\}
$$

onde $\eta_{t+1}$ representa o multiplicador de Lagrange, que é uma função do estado da natureza em $t+1$. As condições de equilíbrio são a condição de lucro zero, 21 , e as condições de primeira ordem necessárias associadas ao problema de otimização.

\subsection{Famílias}

Há um contínuo de famílias, indexadas por $j \in(0,1)$, que consomem, poupam, tomam decisões de portfólio e ofertam o insumo trabalho diferenciado. Elas escolhem seus salários usando uma variante das fricções de Calvo (1983) proposta por Erceg et al. (2000).

As preferências da $j^{\text {th }}$ família são dadas por:

$$
E_{t}^{j} \sum_{l=0}^{\infty} \beta^{l} \zeta_{c, t+l}\left\{u\left(C_{t+l}-b C_{t+l-1}\right)-\psi_{L} \frac{h_{j, t+l}^{1+\sigma_{L}}}{1+\sigma_{L}}-v \frac{\left(\frac{P_{t+l} C_{t+l}}{M_{t+l}}\right)^{1-\sigma_{q}}}{1-\sigma_{q}}\right\}
$$

A família maximiza utilidade sujeita à seguinte restrição orçamentária:

$$
P_{t} C_{t}+B_{t+l}+M_{t+l} \leq\left(1+R_{t}^{e}\right) B_{t}+W_{j, t} h_{j, t}+M_{t}
$$

em que $C_{t}$ representa o consumo, $h_{j, t}$ as horas trabalhadas, $M_{t}$ a moeda, $B_{t}$ os títulos, $R_{t}^{e}$ os juros pagos pelos títulos, $W_{j, t}$ o salário, $P_{t}$ os preços, $\zeta_{c, t}$ o choque nas preferências, $b$ o parâmetro de persistência do hábito, $\psi_{L}$ o de peso da desutilidade do trabalho, $\sigma_{L}$ o de curvatura da desutilidade do trabalho, $v$ o de peso da moeda na utilidade, e $\sigma_{q}$ o de curvatura da moeda na utilidade.

E se depara com a seguinte demanda por trabalho:

$$
h_{j, t}=\left(\frac{W_{j, t}}{W_{t}}\right)^{\frac{\lambda_{w}}{1-\lambda_{w}}} l_{t}, 1 \leq \lambda_{w}
$$

A $j^{\text {th }}$ família otimiza seu salário com probabilidade $1-\xi_{w}$. Com probabilidade $\xi_{w}$, não pode otimizar e fixa o nível de salário do seguinte modo:

$$
W_{j, t}=\tilde{\pi}_{w, t}\left(\mu_{z^{*}}\right)^{1-\vartheta}\left(\mu_{z^{*}, t}\right)^{\vartheta} W_{j, t-1}
$$

onde $0 \leq \vartheta \leq 1$

$$
\tilde{\pi}_{w, t} \equiv\left(\pi_{t}^{\text {target }}\right)^{l_{w}}\left(\pi_{t-1}\right)^{1-l_{w}}, 0<\iota_{w}<1
$$

em que $\pi_{t}^{\text {target }}$ é a meta de inflação da autoridade monetária. O parâmetro $\iota_{w}$ é o peso da meta de inflação nos salários. A família que não otimiza fixa 
o salário de acordo com a meta de inflação $\pi_{t}^{\text {target }}$ ou segundo a inflação do período passado $\pi_{t-1}$.

\subsection{Restrição de Recursos}

O equilíbrio no mercado de bens finais implica que:

$$
\mu \int_{0}^{\bar{\omega}_{t}} \omega d F(\omega)\left(1+R_{t}^{k}\right) \frac{Q_{\bar{K}^{\prime}, t-1} \bar{K}_{t}}{P_{t}}+\frac{\tau_{t}^{o i l} a\left(u_{t}\right)}{Y^{t}}+\frac{\Theta\left(1-\gamma_{t}\right) V_{t}}{P_{t}}+G_{t}+C_{t}+\left(\frac{1}{Y^{t} \mu_{Y, t}}\right) I_{t} \leq Y_{t}
$$

O primeiro objeto em 28 representa o produto final usado nos custos de monitoramento bancário. O segundo termo captura os custos de utilização do capital. O terceiro termo corresponde ao consumo de $\left(1-\gamma_{t}\right)$ empreendedores, os quais saem da economia no período $t$.

O consumo governamental é modelado da seguinte forma:

$$
G_{t}=z^{*} g_{t}
$$

em que $g_{t}$ é um processo estocástico estacionário. Esse modo de modelar $G_{t}$ ajuda a assegurar que o modelo possua uma trajetória de crescimento balanceado. O último termo do lado esquerdo de 30 é a quantidade de bens finais usados para produzir $I_{t}$ bens de investimento. Além do mais, seguindo Yun (1996), deriva-se a relação entre $Y_{t}$ e o capital agregado e a oferta de trabalho agregada das famílias.

O produto nacional bruto (PNB) é dado por:

$$
G D P_{t}=C_{t}+\frac{1}{\Upsilon^{t} \mu_{\Upsilon, t}} I_{t}+G_{t}
$$

Note, mais uma vez, que o choque de tecnologia investimento-específico, $\mu_{\Upsilon, t}$, influência a transformação de bens de consumo em bens de investimento e, assim, entra na expressão do preço relativo do investimento, dada por $\frac{1}{\Upsilon^{t} \mu_{\curlyvee, t}}$.

\subsection{Política Monetária}

Para fechar o modelo, usa-se uma versão generalizada da regra de Taylor. Sobre essa regra, o alvo operacional da política monetária é $R_{t+1}^{e}$, o qual é ajustado de acordo com a seguinte função de reação da autoridade monetária:

$$
\hat{R}_{t+1}^{e}=\begin{aligned}
& \rho_{i} \hat{R}_{t}^{e}+\left(1-\rho_{i}\right) \alpha_{\pi} \frac{\pi}{R^{e}}\left(E_{t}\left(\hat{\pi}_{t+1}\right)-\hat{\pi}_{t}^{\text {target }}\right)+ \\
& \left(1-\rho_{i}\right) \frac{\alpha_{\Delta y}}{4 R^{e}} \log \left(\frac{G D P_{t}}{\mu_{z^{*}} G D P_{t-1}}\right)+\frac{1}{400 R^{e}} \varepsilon_{t}
\end{aligned}
$$

em que $\hat{R}_{t}^{e}$ é a taxa de juros fixada pela autoridade monetária, $\rho_{i}$ é o coeficiente de suavização da taxa de juros, $\alpha_{\pi}$ é o coeficiente de resposta dos juros à inflação, $\alpha_{\Delta y}$ é o coeficiente de resposta dos juros à variação do produto. Além disso, $G D P_{t}$ refere-se ao produto, $\varepsilon_{t}$ ao choque na política monetária, $\mu_{z^{*}}$ à taxa de crescimento da economia, $E_{t}\left(\hat{\pi}_{t+1}\right)$ à inflação esperada e $\hat{\pi}_{t}^{\text {target }}$ à meta de inflação. $\pi$ e $R^{e}$ representam os valores de estado estacionário da inflação e da taxa de juros, respectivamente. 


\section{Resultados}

\subsection{Dados}

O modelo completo, com as condições de primeira ordem que definem o equilíbrio dessa economia, está derivado em Christiano et al. (2010). As variáveis observadas oferecidas ao modelo na estimação bayesiana são trimestrais e cobrem o período de 1995:1 a 2010:4. As séries de PIB, investimento e crédito foram calculadas em primeira diferença do log (taxas de variação) para induzir estacionariedade e substituídas pelas respectivas variáveis dentro do modelo em desvios do estado estacionário. O processo estocástico $\hat{\mu}_{z_{t}^{*}, t}$ é adicionado para permitir que a economia cresça em estado estacionário. As séries observadas são definidas como:

PIB: $g \hat{d} p_{t}-g \hat{d} p_{t-1}+\hat{\mu}_{z_{t}^{*}, t}$. Corresponde à diferença do log do PIB a preços de mercado, calculado pelo IBGE, em relação a sua média. A fonte do PIB a preços de mercado foi o Ipeadata.

Investimento: $\hat{i}_{t}-\hat{i}_{t-1}+\hat{\mu}_{z_{t}^{*}, t}$. É equivalente à diferença do log do Capital fixo, representado por formação bruta de capital, em relação a sua média. A fonte da formação bruta de capital foi o Ipeadata.

Crédito: $\hat{b}_{t}-\hat{b}_{t-1}+\hat{\mu}_{z_{t}^{*}, t}$. Corresponde à diferença do log de operações de crédito ao setor privado em relação a sua média. A fonte de operações de crédito ao setor privado foi o Banco Central do Brasil.

Spread de crédito: $P_{t}^{e}$, é o spread médio das operações de crédito com recursos livres referenciais, representado pela diferença entre a taxa de juros (pré-fixada) à pessoa jurídica e da taxa de juros do Over Selic. Ambas as séries foram obtidas no Banco Central do Brasil.

Inflação: $\hat{\pi}_{t}$, corresponde à primeira diferença do log do IGP-DI, com base $100 \mathrm{em}$ agosto de 1994. A fonte dessa variável foi o Ipeadata.

Com exceção de spread e juros, as demais séries foram deflacionadas usando o IGP-DI e estão em termos per capita. O cálculo da população trimestral foi feito a partir de uma aproximação exponencial da série anual de população residente em $1^{\circ}$ de julho, obtida junto ao IBGE.

\subsection{Estimação}

No processo de estimação bayesiana, foram usadas as séries transformadas do PIB, investimento e crédito juntamente com as séries de spread do crédito e inflação. A essas séries correspondem os choques de política monetária, preço dos investimentos, investimento, risco de mercado e markup de preços.

A escolha desses choques baseou-se na estimação de Christiano et al. (2010) para a economia americana e na literatura recente que busca quantificar a importância relativa de choques alternativos para o ciclo de negócios. Embora os modelos seminais de tradição RBC enfatizem o choque tecnológico, estudos posteriores concluem que choques em outras variáveis são mais relevantes 
para explicar as flutuações macroeconômicas. ${ }^{3}$

O modelo proposto por Justiniano et al. (2010) considera que choques na eficiência marginal do investimento enquadram-se nessa categoria. A justificativa provém da presença de rigidez nominal que não está presente na modelagem RBC. Usando um modelo DSGE com rigidez de preços e salários, conforme Christiano et al. (2005), os autores argumentam que o choque no investimento é o principal responsável pelo ciclo econômico.

A respeito do impacto de choques financeiros na economia americana Nolan \& Thoenissen (2009) calibram um modelo DSGE com fricção financeira segundo Bernanke et al. (1999). Os resultados mostram que choques financeiros são mais importantes para entender os ciclos de negócios que choques de tecnologia ou choques monetários.

Os parâmetros fixados do modelo são reportados na Tabela 2, tendo sido usados valores correspondentes à economia brasileira quando disponíveis. Os parâmetros $\psi_{L}, \sigma_{L}, v, \sigma_{q}, b, \lambda_{w}, \delta, \alpha, \lambda_{f}$ e $\Phi$ são compatíveis com os valores utilizados por Christiano et al. (2010). Para os parâmetros que caracterizam os empreendedores, $\gamma, \mu, F(\bar{\omega})$ e $\operatorname{Var}(\log (\omega))$, adotou-se valores com referência a Bernanke et al. (1999). O valor de $\beta$ foi escolhido para ser compatível com a taxa de juros real brasileira, $\mu_{z}$ para atender ao crescimento médio verificado no período e $\alpha_{\Delta y}$ para refletir o valor consolidado na literatura doméstica.

Tabela 2: Parâmetros do Modelo

\begin{tabular}{clc}
\hline Parâmetro & Definição & Valor \\
\hline$\beta$ & Fator de Desconto & 0,985 \\
$\psi_{L}$ & Peso da Desutilidade do Trabalho & 6,00 \\
$\sigma_{L}$ & Curvatura da Desutilidade do Trabalho & 1,50 \\
$v$ & Peso da Moeda na Utilidade & 0,001 \\
$\sigma_{q}$ & Curvatura da Moeda na Utilidade & $-6,00$ \\
$b$ & Parâmetro de Persistência do Hábito & 0,70 \\
$\lambda_{w}$ & Markup de Steady State, Ofertantes de Trabalho & 1,05 \\
$\mu_{z}$ & Taxa de Crescimento da Economia (Anual) & 2,15 \\
$\delta$ & Taxa de Depreciação & 0,025 \\
$\alpha$ & Participação do Capital na Função de Produção & 0,36 \\
$\lambda_{f}$ & Markup de Steady State, Firmas de Bens Intermediários & 1,20 \\
$\Phi$ & Custo Fixo para Firmas de Bens Intermediários & 0,23 \\
$\gamma$ & Percentual de Empreendedores que Sobrevivem entre Períodos & 97,62 \\
$\mu$ & Fração dos Lucros Realizados Perdidos na Falência & 0,99 \\
$F(\bar{\omega})$ & Percentual dos Negócios que vão a Falência em um Trimestre & 0,20 \\
$\operatorname{Var}(\log (\omega))$ & Variância do (Normal Dist.) Log do Parâmetro de Produtividade & 0,24 \\
& Idiossincrático & 0,50 \\
$\alpha_{\Delta y}$ & Coeficiente da Variação do Produto na Regra de Taylor & \\
\hline
\end{tabular}

Fonte: Elaboração própria.

A Tabela 3 reporta os resultados da estimação. Os parâmetros $\iota$ e $\iota^{w}$, os quais se referem à indexação, não se distanciaram dos valores prioris. Isso ocorreu porque, conforme ilustra a Figura 1, foram os únicos casos em que os dados não conseguiram agregar informações ao modelo. ${ }^{4}$ Por outro lado, os coeficientes de Calvo apresentaram valores reduzidos, indicando que existe relativa flexibilidade de preços e salários no Brasil. O coeficiente de resposta da taxa de juros à inflação na regra de Taylor, $\alpha_{\pi}$, revela que a autoridade monetária responde agressivamente a desvios da inflação em relação à meta. Já

\footnotetext{
${ }^{3}$ King \& Rebelo (1999) fornecem uma discussão detalhada sobre o tema.

${ }^{4}$ Essa constatação decorre do fato de que a distribuição priori pouco difere da posteriori.
} 
o coeficiente da taxa de juros defasada, $\rho_{i}$, indica que há uma preocupação com a suavização dos ajustes no instrumento de política monetária. O ajustamento do investimento tem valor compatível com Christiano et al. (2010). A persistência $(\rho)$ e o erro padrão do choque no risco $\left(\sigma_{t}\right)$ sugerem que o risco de mercado possui papel relevante para explicar a dinâmica da economia. Os choques no preço dos investimentos e nos investimentos tiveram erros padrão estimados elevados. Essa evidência mostra que o investimento é bastante volátil, contribuindo para replicar períodos de instabilidade observados na economia.

Comparando os valores reportados na Tabela $3 \mathrm{com}$ as estimativas de Christiano et al. (2010) para a economia americana, no caso do modelo com o acelerador financeiro, destacam-se uma maior resposta dos juros à inflação, uma maior persistência do risco de mercado e elevada variância dos preços e da eficiência dos investimentos no caso da economia brasileira. Os respectivos valores para os Estados Unidos são 1,817 para $\alpha_{\pi}, 0,722$ para o termo autoregressivo de $\sigma_{t}, 0,003$ para o erro-padrão de $\mu_{\Upsilon, t}$ e 0,019 para o erro-padrão de $\zeta_{i, t}$. O valor estimado do coeficiente de Calvo de preços, $\xi_{p}=0$, 3, está abaixo da estimativa de 0,702 obtida por Christiano et al. (2010). ${ }^{5}$ Esse valor revela a ocorrência de em um reajuste de preços a cada 1,4 trimestre, em média, sendo coerente com as estimativas de Gouvea (2007) e Barros et al. (2009) usando microdados. Para a economia americana, porém, Bils \& Klenow (2004) e Golosov \& Lucas (2007) encontram um reajuste de preços, em média, a cada 4 trimestres.

\subsection{Importância Relativa dos Choques}

A Figura 2 ilustra a reconstrução dos choques suavizados a partir do modelo estimado. Algumas evidências interessantes podem ser observadas. Primeiro, não se conseguiu encontrar um padrão de choque para o preço do investimento. Foi possível, contudo, capturar um período de extrema volatilidade na eficiência marginal do investimento. Essa elevada instabilidade ocorreu, justamente, durante a crise financeira global de 2008-2009, reforçando o entendimento de que o abalo no setor financeiro afetou o lado real da economia brasileira naquele momento. Essa maior volatilidade na eficiência marginal do investimento foi acompanhada de choques no risco de mercado, cujas variações acompanharam o período de instabilidade financeira. O risco de mercado apresentou maior relevância para a dinâmica da economia brasileira nos períodos pré-eleitoral de 2002 e durante a crise financeira global de 2008-2009. Percebe-se clara diferença entre os dois períodos com relação à dinâmica dos preços e à resposta da autoridade monetária aos eventos.

Em 2002, houve uma forte oscilação no risco de mercado e no markup de preços. Inicialmente, o markup de preços subiu até alcançar seu maior nível e, em seguida, caiu até atingir o menor valor do período. O choque suavizado da política monetária revela uma oscilação oposta no mesmo período, com uma forte queda e subsequente aumento. Dessa forma, o Banco Central agiu em conformidade com as recomendações usuais de política, segundo as quais elevações no markup devem ser enfrentadas com afrouxamento monetário enquanto quedas no markup requerem aperto monetário.

\footnotetext{
${ }^{5} \mathrm{O}$ valor estimado de 0,3 está próximo do valor de 0,375 usado como priori por Christiano et al. (2010).
} 


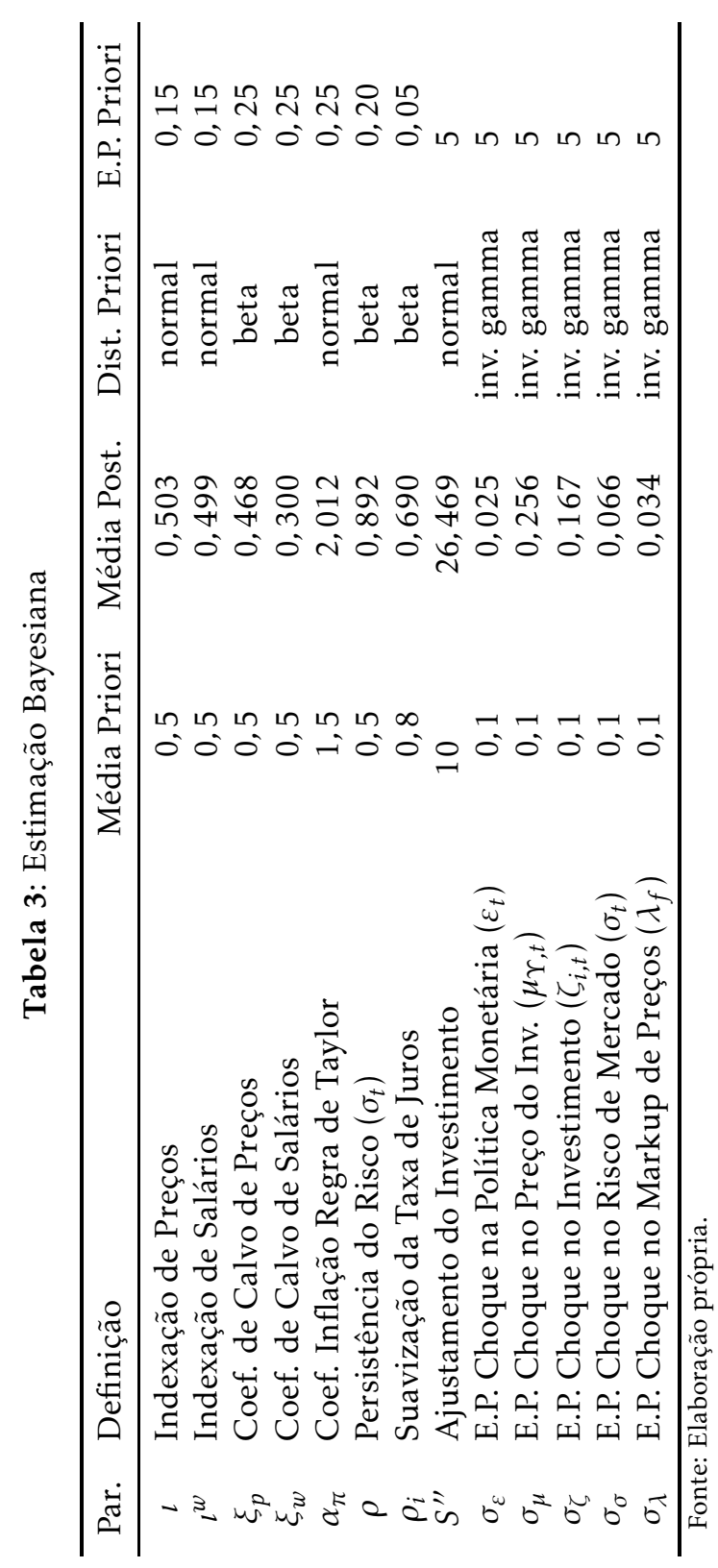



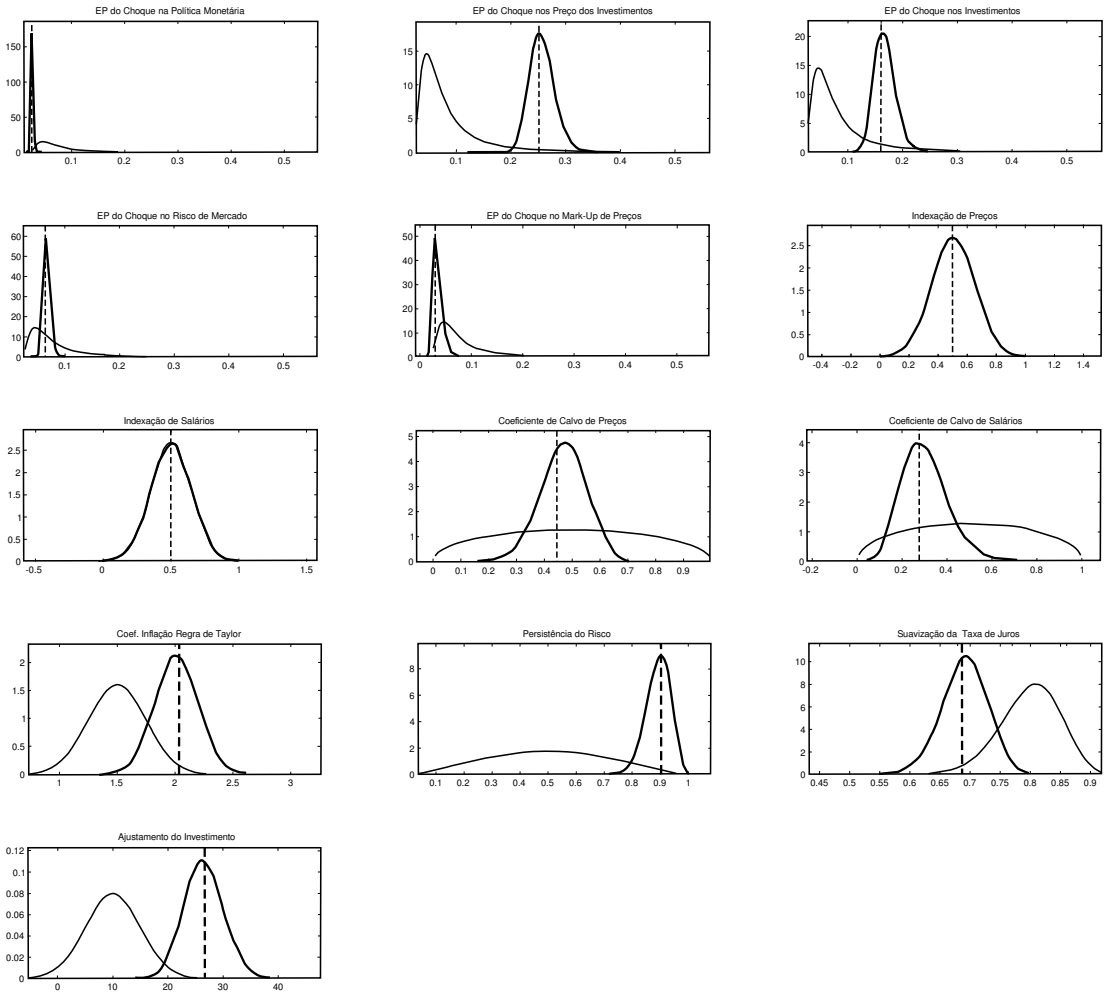

Figura 1: Prioris (linha fina) e posterioris (linha cheia) dos parâmetros estimados

No episódio da crise internacional de 2008-2009, porém, o Banco Central parece não ter seguido essa mesma estratégia. Diante de uma oscilação que provocou queda e subsequente aumento do markup, houve um movimento na mesma direção do choque suavizado da política monetária. Esse comportamento da autoridade monetária sugere uma mudança em relação à política adotada durante o período eleitoral de 2002.
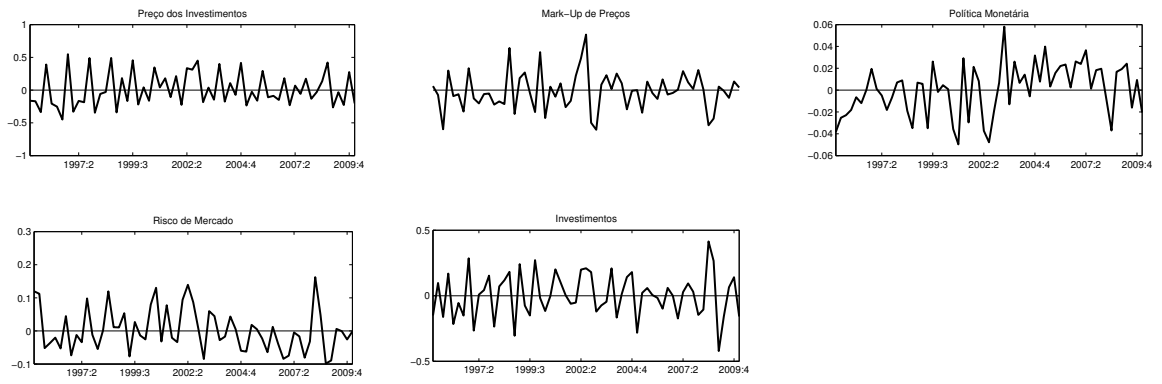

Figura 2: Choques Suavizados

Complementando essa análise, a decomposição de variância de algumas séries do modelo é reportada na Tabela 4. Essa decomposição calcula a contribuição total de cada choque para explicar variações nas séries do modelo durante todo o período. Não é possível, portanto, focar em episódios específicos tal qual os choques suavizados. O choque na eficiência marginal do investimento 
apresentou maior capacidade para explicar as flutuações nas variáveis endógenas, confirmando as evidências de Justiniano et al. (2010) e Araújo (2012). O choque no preço do investimento aparece como segunda maior fonte de contribuição. Os demais choques apresentaram contribuições mais localizadas por causa de restrições em suas transmissões impostas pela estrutura teórica do modelo. Dessa forma, o choque no markup de preços foi relevante para explicar variações na inflação e na taxa de juros, enquanto o choque na política monetária foi representativo para variações na taxa de juros. Por fim, o choque no risco de mercado contribuiu para explicar as variações no prêmio de risco.

Essa evidência é diferente dos resultados encontrados por Christiano et al. (2010). No caso da economia americana, os choques na eficiência marginal do investimento e no preço do investimento revelaram pouca relevância na decomposição de variância das séries no modelo com acelerador financeiro. Por outro lado, o choque no markup de preços teve papel de destaque, seguido pelo choque de política monetária. A semelhança com o caso brasileiro fica por conta do choque no risco de mercado que, em ambos os países, contribui para explicar somente o prêmio de risco. A explicação para essas diferenças pode estar na combinação de dois elementos, representados pela estrutura mais rica do modelo estimado para a economia americana, que usou 11 variáveis observadas, e nas particularidades da economia brasileira onde, conforme notado também por Araújo (2012), os choques no investimento são importantes para explicar o ciclo de negócios. Isso não impede, contudo, que outros choques ganhem importância em períodos específicos, como aconteceu no período eleitoral de 2002 e na crise internacional de 2008-2009.

\subsection{Funções Impulso-Resposta}

A partir da estimação do modelo, foram construídas funções de impulso resposta bayesianas. Essas representam a dinâmica das principais variáveis macroeconômicas a partir de um choque exógeno. Diante da evidência reportada na seção anterior acerca da relevância de cada choque suavizado, foi analisado como as séries de tempo reagem a choque de um desvio padrão no risco de mercado $\left(\sigma_{t}\right)$, na política monetária $\left(\varepsilon_{t}\right)$, nos investimentos $\left(\zeta_{i, t}\right)$ e no preço dos investimentos $\left(\mu_{\Upsilon, t}\right)$.

\subsection{Choque no Risco de Mercado}

A Figura 3 ilustra o que ocorre com a dinâmica da economia quando o risco de mercado $\left(\sigma_{t}\right)$ aumenta. Esse aumento afeta a realização da variável aleatória $\omega$, caracterizando que os empreendimentos estão mais arriscados. Primeiramente, o prêmio de risco se eleva, ou seja, os bancos cobram um maior retorno dos empreendimentos dado o nível maior de risco. Esse comportamento está incorporado na equação 20 do prêmio de risco. O aumento do prêmio reduz a oferta de empréstimos pela equação 21 , reduzindo o investimento e o produto. A menor oferta de produto, por sua vez, aumenta a inflação, levando a autoridade monetária a elevar os juros por 33. Isso contribui para diminuir o prêmio de risco por meio da redução da riqueza dos empreendedores $\left(\bar{N}_{t+1}\right)$ em (19), o que diminui o prêmio de risco por $\left(\bar{N}_{t}\right)$ em 20. Repare que a interação entre as equações 19 e 20 envolvem $\left(\bar{N}_{t+1}\right)$ e $\left(\bar{N}_{t}\right)$, ou seja, a riqueza líquida em dois períodos diferentes. Isso explica o fato de a função de impulso resposta para 


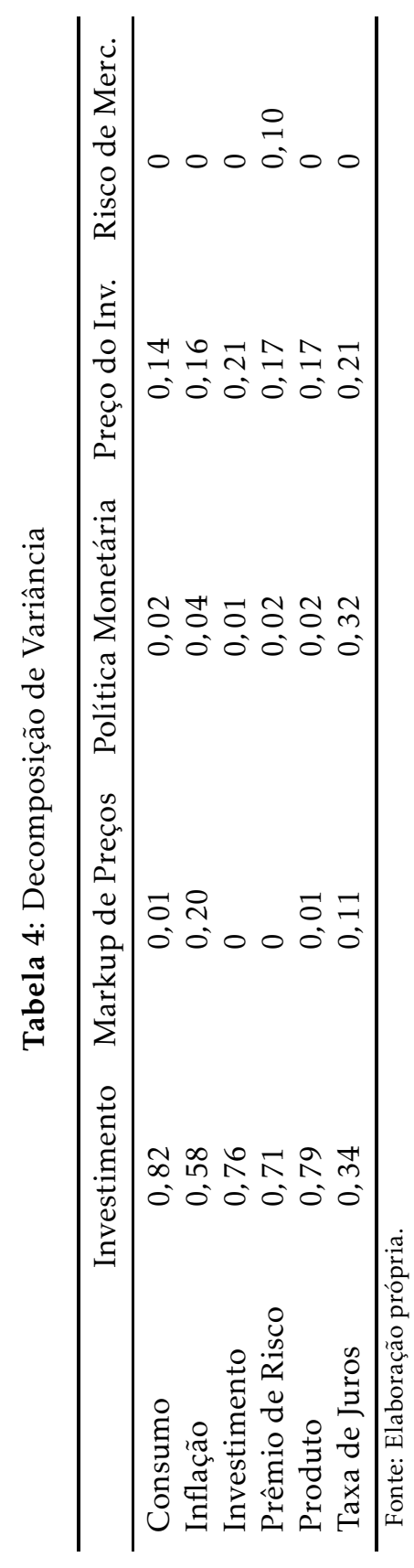


o prêmio de risco ter um impacto inicial positivo e convergência lenta. $\mathrm{Na}$ medida em que o prêmio de risco diminui, o produto e o investimento, que tiveram um declínio suave, apresentam também convergência lenta. Nesse cenário, o produto não cai mais porque a elevação do consumo demanda mais produção. Isso é decorrente da hipótese dos depósitos das famílias serem insumo para os empréstimos bancários. A menor oferta de empréstimos implica, em equilíbrio, em menores depósitos que induzem ao maior consumo pelas famílias. O declínio nos investimentos reduz, também, os custos de ajustamento do estoque de capital, isto é, menos recursos são necessários para se realizar um investimento. A redução nos custos de ajustamento, portanto, contribui para o aumento no consumo a partir de um choque no risco de mercado.
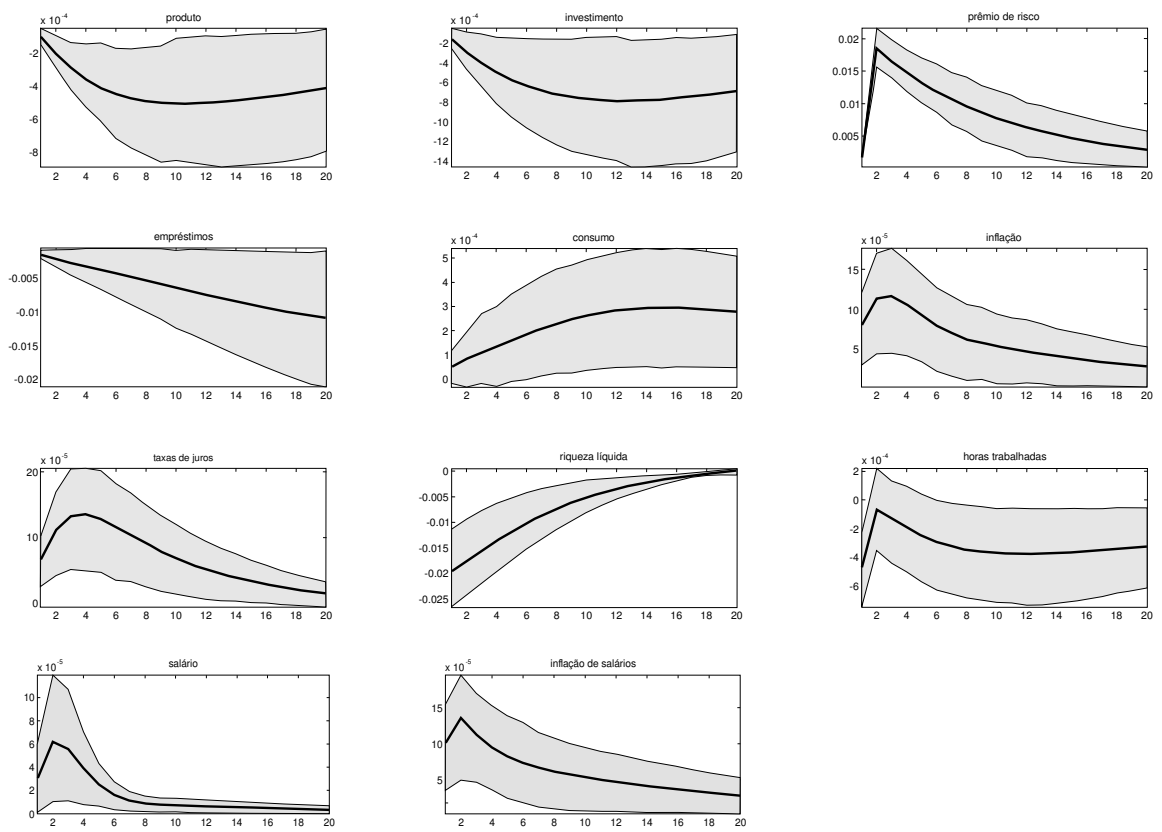

Figura 3: Impulso-Resposta Bayesiana - Choque no Risco

\subsection{Choque na Política Monetária}

Os efeitos de um choque na política monetária estão representados na Figura 4. O choque em $\varepsilon_{t}$ aumenta os juros pela regra de Taylor da equação 33. A elevação inesperada dos juros faz os bancos aumentarem os juros dos empréstimos bancários $\left(Z_{t+1}\right)$ e o valor dos empréstimos $\left(B_{t+1}\right)$ por 21 . Para a equação 18 continuar em equilíbrio é necessário que a taxa de retorno do capital para os empreendedores $\left(R_{t+1}^{k}\right)$ também aumente. Esse aumento em $R_{t+1}^{k}$ eleva o prêmio de risco por 20. Consequentemente, um maior prêmio de risco reduz a riqueza líquida dos empreendedores $\left(\bar{N}_{t+1}\right)$ por 19 , diminuindo a disponibilidade de recursos para investimento e geração de produto na economia. Desse modo, a demanda por empréstimos para financiar as atividades empresariais aumenta por 18. Essa elevação nos empréstimos ocorre de forma hump-shaped, fazendo com que o produto e o investimento se recuperem de forma semelhante. Nessa situação, o consumo se reduz com a elevação dos empréstimos, pois mais depósitos das famílias são demandados. A política 
monetária tem, nesse caso, efeitos negativos sobre o produto, investimento e consumo, os quais se recuperam pelo canal do crédito. A redução quase linear do prêmio de risco posteriormente ao choque na taxa de juros acompanha a recuperação do crédito e das demais variáveis macroeconômicas do modelo.
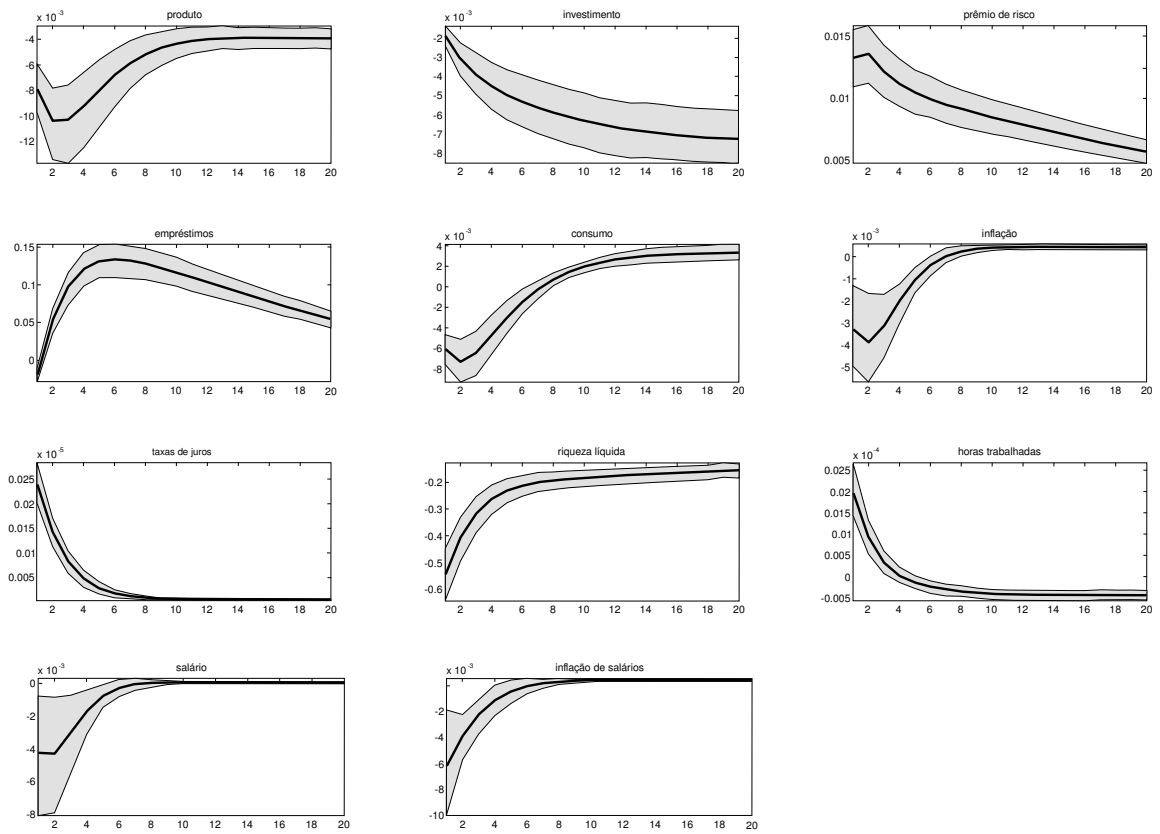

Figura 4: Impulso-Resposta Bayesiana — Choque na Política Monetária

\subsection{Choques nos Investimentos}

A Figura 5 apresenta a dinâmica resultante de um choque nos investimentos, em que um choque positivo representa uma redução na eficiência marginal do investimento que aumenta os custos de instalação, de acordo com a equação 9 . A elevação dos custos, por sua vez, reduz os investimentos e o produto. Na medida em que os investimentos decrescem, os custos de ajustamento reduzem e o consumo aumenta. O consumo mais elevado impacta positivamente na inflação e proporciona um declínio mais suave do produto. A menor oferta de produto também aumenta a inflação, levando a autoridade monetária a elevar os juros pela equação 33. O aumento dos juros induz os bancos a elevarem os juros dos empréstimos pela equação 21 , o que causa uma redução na demanda por empréstimos. O menor volume de investimentos e de empréstimos reduzem o prêmio de risco por 20, o que ocasiona uma elevação da riqueza líquida $\left(\bar{N}_{t+1}\right)$ em 19 . Assim, a redução do prêmio de risco aumenta a riqueza líquida, a qual contribui para que o investimento e o produto revertam as trajetórias de queda.

Os impactos de um choque no preço dos investimentos estão ilustrados na Figura 6. O choque causa uma redução relativa no preço para transformar bens de consumo em bens de investimento. Desse modo um choque positivo causa redução no preço dos investimentos e redução do produto conforme a equação 32. A redução no preço, por sua vez, estimula novos investimentos pela condição de maximização de lucros dos produtores de capital 10. O 

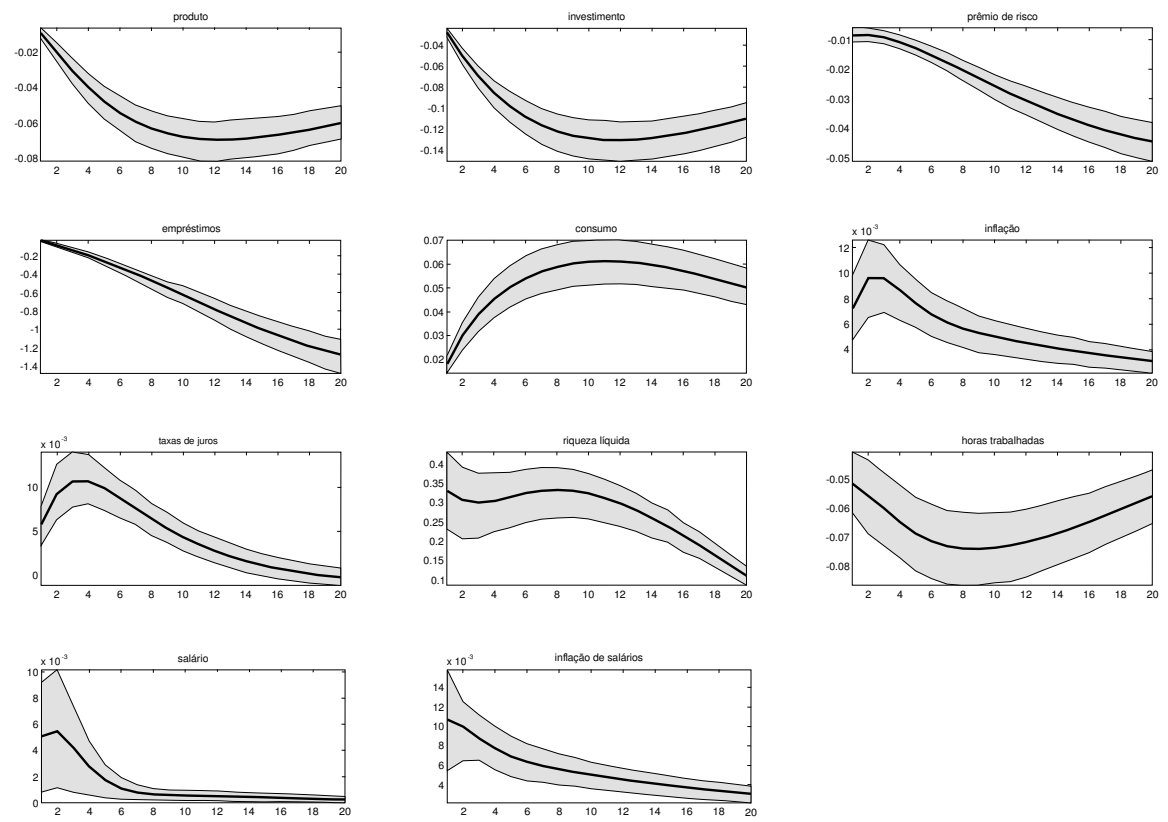

Figura 5: Impulso-Resposta Bayesiana - Choque nos Investimentos

maior volume de investimentos aumenta os custos de ajustamento do capital reduzindo o consumo. A diminuição do consumo reduz a inflação, induzindo a autoridade monetária a reduzir os juros pela equação 33. O declínio dos juros faz os bancos diminuírem os juros dos empréstimos bancários $\left(Z_{t+1}\right)$ e a elevação dos investimentos aumenta a demanda por bens de capital. Ambas as forças estimulam os empréstimos pela equação 18. A elevação na demanda por empréstimos proporciona um aumento no retorno das atividades empresariais $\left(R_{t+1}^{k}\right)$ causando um crescimento no prêmio de risco pela equação 20. Desse modo, o aumento no prêmio de risco reduz a riqueza líquida dos empreendedores $\left(\bar{N}_{t+1}\right)$ por 19 , atenuando a expansão dos investimentos e a recuperação do produto.

\section{Considerações Finais}

O propósito deste artigo foi estimar o modelo DSGE proposto por Christiano et al. (2010) para a economia brasileira, o qual possui a estrutura de acelerador financeiro presente em Bernanke et al. (1999), visando avaliar os impactos de choques no prêmio de risco, na política monetária e nos investimentos sobre o ciclo econômico doméstico. Realizou-se uma estimação bayesiana do referido modelo, usando séries temporais de PIB, investimento, crédito, spread do crédito e inflação no período pós-plano real. A partir do modelo estimado, foram computados e analisados choques suavizados, decomposição de variância e funções impulso-resposta. Os resultados indicam que os choques considerados no modelo contribuíram para explicar a dinâmica macroeconômica da economia brasileira no período.

A estimação bayesiana revelou que o Banco Central respondeu de forma agressiva aos aumentos da inflação em relação à meta no período recente. Constatou-se, também, que no processo eleitoral de 2002 e na crise internaci- 

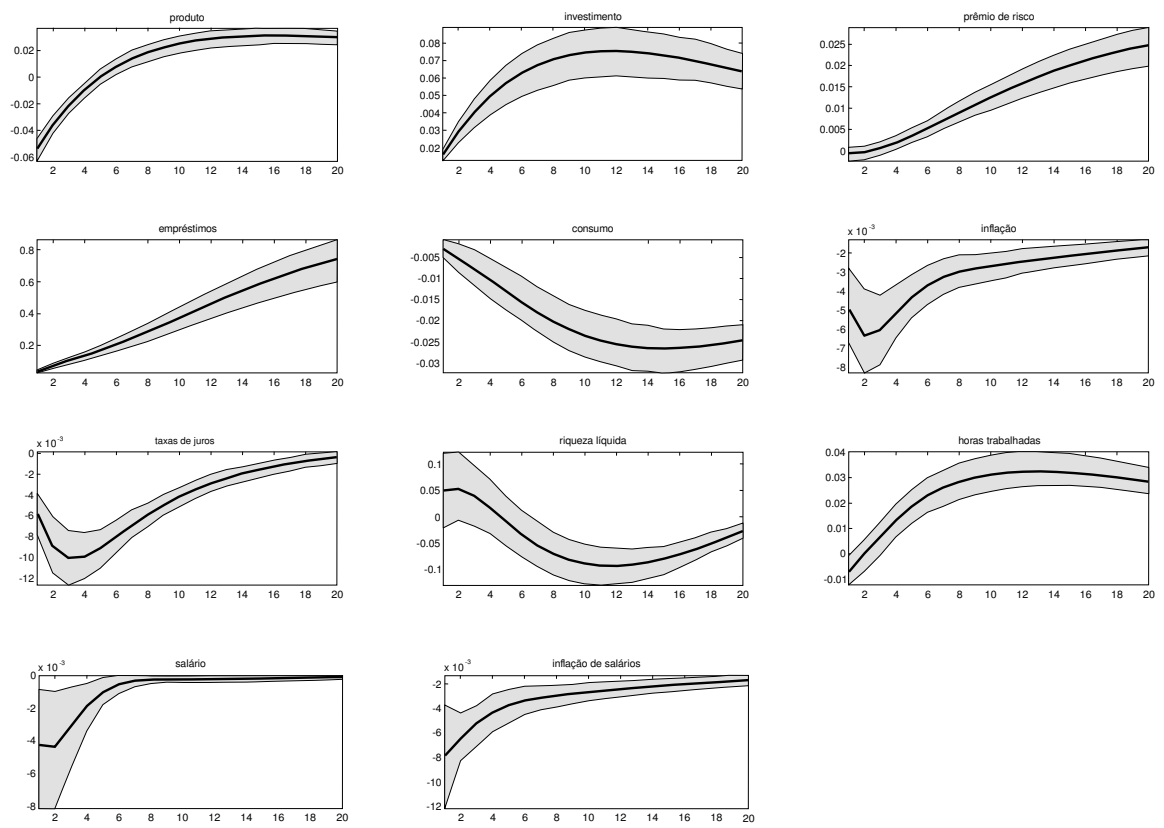

Figura 6: Impulso-Resposta Bayesiana - Choque no Preço dos Investimentos

onal de 2008-2009 o markup de preços e o risco de mercado foram relevantes para explicar a dinâmica da economia. No primeiro evento, o Banco Central seguiu o receituário convencional, promovendo restrição monetária durante quedas no markup, e expansão monetária quando o markup aumentou. Já no segundo episódio, agiu contrariamente a essa recomendação de política, com o choque suavizado de política monetária acompanhando o choque suavizado no markup de preços. Além disso, choques no preço e na eficiência marginal do investimento confirmaram o caráter volátil do investimento, constituindose nos principais fatores para explicar as flutuações econômicas no período como um todo.

As funções impulso-resposta a choques no risco de mercado, na política monetária e nos investimentos permitiram avaliar as dinâmicas do produto, consumo, investimento e crédito após as perturbações. Em todos os cenários analisados, houve mudanças no prêmio de risco das atividades empresariais, afetando o volume de empréstimos e produzindo efeitos sobre o consumo, investimento e produto. Dessa forma, o prêmio de risco é uma variável relevante para explicar o ciclo macroeconômico via determinação do crédito.

Um choque positivo no prêmio de risco, devido ao aumento na incerteza sobre aos empreendimentos privados, reduz a oferta de crédito. Essa restrição ao crédito afeta o investimento, o produto e, consequentemente, a inflação. A autoridade monetária reage alterando a taxa de juros que, por sua vez, impacta diretamente no prêmio de risco. Assim, o canal de transmissão da política monetária não é somente via demanda agregada, mas também por meio do mercado de crédito que depende da estabilização do prêmio de risco.

Um choque de política monetária, que aumenta inesperadamente a taxa de juros básica da economia, por outro lado, reduz o produto, o consumo, a inflação, o investimento e eleva o prêmio de risco. Na medida em que a taxa juros retorna ao equilíbrio, o prêmio de risco reduz e o volume de empréstimos 
aumenta, contribuindo para a recuperação do nível de atividade econômica. Assim, a recuperação econômica é alavancada pelo aumento do crédito, que responde positivamente à redução nos juros cobrados dos empreendimentos privados, acompanhando a trajetória de redução no prêmio de risco. Isso sugere que a política monetária pode ser usada para reduzir o prêmio de risco de mercado, estabilizando o investimento, produto e inflação. A autoridade monetária, ao editar políticas de estabilização, deve considerar a interação de tais medidas com o prêmio de risco de mercado, que é um canal de transmissão para a política monetária via mercado de crédito.

A relevância do investimento para explicar a dinâmica do ciclo econômico brasileiro também foi constatada. Choques na eficiência marginal e no preço do investimento provocam alterações no custo de ajustamento do estoque de capital, o que impacta na produção e consumo. O descompasso entre essas variáveis reflete-se na inflação, que pode aumentar ou reduzir dependendo da direção do choque no investimento. Ao alterar a taxa de juros para estabilizar a inflação, a autoridade monetária afeta o spread da taxa de juros, a demanda por empréstimos e o prêmio de risco. Como resultado, a riqueza liquída também é afetada, contribuindo decisivamente para que o investimento e o produto retornem às suas trajetórias de equilíbrio. Essa evidência coaduna com Justiniano et al. (2010), que argumentam que os choques na eficiência marginal do investimento estão entre os principais responsáveis pelo ciclo econômico.

\section{Agradecimentos}

Os autores agradecem a dois pareceristas anônimos e ao Editor Associado Irineu Carvalho Filho, pelos valiosos comentários e sugestões. J. A. Divino agradece ao $\mathrm{CNPq}$ pelo apoio financeiro. Qualquer erro remanescente é de responsabilidade exclusiva dos autores.

\section{Referências Bibliográficas}

Araújo, E. (2012), 'Investment-specific shocks and real business cycles in emerging economies: Evidence from brazil', Economic Modelling 29(3), 671678.

Barros, R., Bonomo, M., Carvalho, C. \& Matos, S. (2009), Price setting in a variable macroeconomic enviroment: Evidence from brazilian cpi, Texto para discussão, Fundação Getúlio Vargas.

Bernanke, B., Gertler, M. \& Gilchrist, S. (1996), 'The financial accelerator and the flight to quality', The Review of Economics and Statistics 78(1), 1-15.

Bernanke, B., Gertler, M. \& Gilchrist, S. (1999), The financial accelerator in a quantitative business cycle framework, in J. B. Taylor \& M. Woodford, eds, 'Handbook of Macroeconomics', Vol. 1, Elsevier, chapter 21, pp. 1341-93.

Bils, M. \& Klenow, P. J. (2004), 'Some evidence on the importance of sticky prices', Journal of Political Economy 112(5), 947-985.

Calvo, G. A. (1983), 'Staggered prices in a utility-maximizing framework', Journal of Monetary Economics 12(3), 383-398. 
Carvalho, F. A. \& Valli, M. (2011), Fiscal policy in brazil through the lens of an estimated dsge model, Working Papers Series 240, Central Bank of Brazil, Research Department.

Christensen, I. \& Dib, A. (2008), 'The financial accelerator in an estimated new keynesian model', Review of Economic Dynamics 11(1), 155-178.

Christiano, L. J., Eichenbaum, M. \& Evans, C. L. (2005), 'Nominal rigidities and the dynamic effects of a shock to monetary policy', Journal of Political Economy 113(1), 1-45.

Christiano, L., Motto, R. \& Rostagno, M. (2010), Financial factors in economic fluctuations, Working Paper Series 1192, European Central Bank.

De Castro, M. R., Gouvea, S. N., Minella, A., Dos Santos, R. C. \& SouzaSobrinho, N. F. (2011), Samba: Stochastic analytical model with a bayesian approach, Working Papers Series 239, Central Bank of Brazil, Research Department.

De Graeve, F. (2008), 'The external finance premium and the macroeconomy: Us post-wwii evidence', Journal of Economic Dynamics and Control 32(11), 3415-3440.

Del Negro, M. \& Schorfheide, F. (2010), 'Bayesian macroeconometrics', Prepared for Handbook of Bayesian Econometrics .

Erceg, C. J., Henderson, D. W. \& Levin, A. T. (2000), 'Optimal monetary policy with staggered wage and price contracts', Journal of Monetary Economics 46(2), 281-313.

Fernández-Villaverde, J. (2010), 'The econometrics of dsge models', SERIEs 1(1), 3-49.

Furlani, L. G. C., Portugal, M. S. \& Laurini, M. P. (2010), 'Exchange rate movements and monetary policy in brazil: Econometric and simulation evidence', Economic Modelling 27(1), 284-295.

Golosov, M. \& Lucas, R. E. J. (2007), 'Menu costs and phillips curves', Journal of Political Economy 115, 171-199.

Gouvea, S. (2007), Price rigidity in brazil: Evidence from cpi micro data, Working Papers Series 143, Central Bank of Brazil, Research Department.

Justiniano, A., Primiceri, G. E. \& Tambalotti, A. (2010), 'Investment shocks and business cycles', Journal of Monetary Economics 57(2), 132-145.

Kanczuk, F. (2004), 'Real interest rates and brazilian business cycles', Review of Economic Dynamics 7(2), 436-455.

King, R. G. \& Rebelo, S. T. (1999), Resuscitating real business cycles, in J. B. Taylor \& M. Woodford, eds, 'Handbook of Macroeconomics', Vol. 1 of Handbook of Macroeconomics, Elsevier, chapter 14, pp. 927-1007.

Nolan, C. \& Thoenissen, C. (2009), 'Financial shocks and the us business cycle', Journal of Monetary Economics 56(4), 596-604. 
Nunes, A. F. N. d. \& Portugal, M. S. (2009), Política fiscal e monetária ativas e passivas: uma análise para o brasil pós-metas de inflação, Proceedings of the 37th brazilian economics meeting, ANPEC - Brazilian Association of Graduate Programs in Economics.

Silveira, M. A. (2008), 'Using a bayesian approach to estimate and compare new keynesian dsge models for the brazilian economy: the role for endogenous persistence', Revista Brasileira de Economia 62(3), 333-357.

Silveira, M. A. C. (2006), A small open economy as a limit case of a twocountry new keynesian dsge model: A bayesian estimation with brazilian data, Discussion Papers 1252, Instituto de Pesquisa Econômica Aplicada IPEA.

Sin, H. L. \& Gaglianone, W. P. (2006), Stochastic simulation of a dsge model for brazil, MPRA Paper 20853, University Library of Munich, Germany.

Smets, F. \& Wouters, R. (2003), 'An estimated dynamic stochastic general equilibrium model of the euro area', Journal of the European Economic Association 1(5), 1123-1175.

Smets, F. \& Wouters, R. (2007), 'Shocks and frictions in us business cycles: A bayesian dsge approach', American Economic Review 97(3), 586-606.

Souza-Sobrinho, N. F. (2003), Uma avaliação do canal de crédito no brasil, MPRA Paper 5160, University Library of Munich, Germany.

Souza-Sobrinho, N. F. (2011), 'The role of interest rates in the brazilian business cycles', Revista Brasileira de Economia 65(3), 315-336.

Townsend, R. M. (1979), 'Optimal contracts and competitive markets with costly state verification', Journal of Economic Theory 21, 265-293.

Valli, M. \& Carvalho, F. A. (2010), Fiscal and monetary policy interaction: a simulation based analysis of a two-country new keynesian dsge model with heterogeneous households, Working Papers Series 204, Central Bank of Brazil, Research Department.

Yun, T. (1996), 'Nominal price rigidity, money supply endogeneity, and business cycles', Journal of Monetary Economics 37(2-3), 345-370.

Zerbini, B. M. \& Fabiana, R. (2002), 'Private sector credit and inflation during brazilian stabilization plans: Models with endogenously determined structural breaks', Brazilian Review of Econometrics 22(2), 183-214. 


\section{Apêndice A Estimação Bayesiana}

O modelo DSGE é composto por equações que representam a dinâmica da economia. Tem-se, basicamente, três tipos de variáveis compondo essas equações: variáveis de controle $\left(y_{t}\right)$, variáveis de estado $\left(s_{t}\right)$, e inovações $\left(\epsilon_{t}\right){ }^{6}$ As equações que relacionam as variáveis de estado são chamadas de equações de transição, e possuem representação:

$$
s_{t}=\Phi\left(s_{t-1}, \epsilon_{t} ; \theta\right)
$$

As equações que relacionam as variáveis de controle são chamadas de equações mensuráveis, e possuem representação:

$$
y_{t}=\Psi\left(\alpha, t, s_{t} ; \theta\right)
$$

em que $\theta$ representa os parâmetros estruturais do modelo, $t$ representa variáveis de tendência, e $\alpha$ variáveis que determinam o estado estacionário.

No caso de equações lineares, podemos escrever essas duas equações como:

$$
\begin{gathered}
s_{t}=\Phi_{1}(\theta) s_{t-1}+\Phi_{\epsilon}(\theta) \epsilon_{t} \\
y_{t}=\Psi_{0}(\theta)+\Psi_{1}(\theta) t+\Psi_{2}(\theta) s_{t}
\end{gathered}
$$

O sistema de matrizes $\Phi_{1}, \Phi_{\epsilon}, \Psi_{0}, \Psi_{1}, \Psi_{2}$ é função dos parâmetros do modelo DSGE. O sistema de equações em espaço de estados será, portanto, um sistema de equações em diferenças com equações de transição, equações mensuráveis e equações que fornecem a dinâmica das inovações.

Uma representação em espaço de estados pode ser expressa do seguinte modo:

$$
\begin{gathered}
s_{t}=A s_{t-1}+B \epsilon_{t} \\
y_{t}=C s_{t}+D \epsilon_{t} \\
\epsilon_{t} \sim N(0, I)
\end{gathered}
$$

Vamos definir as projeções lineares $s_{t \mid t-1}=E\left(s_{t} \mid Y_{t-1}\right)$ e $s_{t \mid t}=E\left(s_{t} \mid Y_{t}\right)$, onde $Y_{t}=y_{1}, y_{2}, \ldots, y_{t}$ e o sub-índice se refere ao conjunto condicionante (i.e. $t \mid t-1$ significa um desenho de momento $t$ condicionado à informação disponível em $t-1)$. Também, temos matrizes de variâncias e covariâncias $P_{t-1 \mid t-1}=$ $E\left(s_{t-1}-s_{t-1 \mid t-1}\right)\left(s_{t-1}-s_{t-1 \mid t-1}\right)^{\prime}$ e $P_{t \mid t-1}=E\left(s_{t-1}-s_{t \mid t-1}\right)\left(s_{t-1}-s_{t \mid t-1}\right)^{\prime}$.

Dadas essas projeções lineares e a estrutura Gaussiana da representação em espaço de estados, o erro de previsão de uma passo a frente, $\eta_{t}=y_{t}-C s_{t \mid t-1}$, é ruído branco. Projetando a evolução dos estados:

$$
s_{t \mid t-1}=A s_{t-1 \mid t-1}
$$

Desde que a possível presença de correlação entre as inovacões não mude a natureza do filtro, temos que:

$$
s_{t \mid t}=s_{t \mid t-1}+K \eta_{t}
$$

\footnotetext{
${ }^{6}$ Esta metodologia de estimação segue o trabalho de Del Negro \& Schorfheide (2010) e Fernández-Villaverde (2010).
} 
em que $K$ é o ganho de Kalman no tempo $t$. Defina a variância da previsão como $V_{y}=C P_{t \mid t-1} C^{\prime}+D D^{\prime}$.

Desde que $\eta_{t}$ seja ruído branco, a verossimilhança condicional da observação do período é:

$$
\log p\left(y_{t} \mid \theta\right)=-\frac{n}{2} \log 2 \pi-\frac{1}{2} \log \operatorname{det}\left(V_{y}\right)-\frac{1}{2} \eta_{t} V_{y}^{-1} \eta_{t}
$$

O último passo é atualizar as estimativas dos estados. Defina os resíduos $\xi_{t \mid t-1}=s_{t}-s_{t \mid t-1}$ e $\xi_{t \mid t}=s_{t}-s_{t \mid t}$. Subtraindo a equação (36) da equação (37) produz:

$$
\begin{gathered}
s_{t}-s_{t \mid t-1}=A\left(s_{t-1}-s_{t-1 \mid t-1}\right)+B w_{t} \\
\xi_{t \mid t-1}=A \xi_{t-1 \mid t-1}+B w_{t}
\end{gathered}
$$

Subtraindo (37) de (34), resulta:

$$
\begin{gathered}
s_{t}-s_{t \mid t}=s_{t}-s_{t \mid t-1}-K\left[C s_{t}+D w_{t}-C s_{t \mid t-1}\right] \\
\xi_{t \mid t}=\xi t \mid t-1-K\left[C \xi_{t \mid t-1}+D w_{t}\right]
\end{gathered}
$$

Note que $P_{t \mid t-1}$ pode ser escrito como:

$$
\begin{aligned}
P_{t \mid t-1} & =E \xi_{t \mid t-1} \xi_{t \mid t-1}^{\prime} \\
& =E\left(A \xi_{t-1 \mid t-1}+B w_{t}\right)\left(A \xi_{t-1 \mid t-1}+B w_{t}\right)^{\prime} \\
& =A P_{t-1 \mid t-1} A^{\prime}+B B^{\prime}
\end{aligned}
$$

e para $P_{t \mid t}$ temos

$$
\begin{aligned}
P_{t \mid t} & =E \xi_{t \mid t} \xi_{t \mid t}^{\prime} \\
& =E\left(\xi_{t \mid t-1}-K\left[C \xi_{t \mid t-1}+D w_{t}\right]\right)\left(\xi_{t \mid t-1}-K\left[C \xi_{t \mid t-1}+D w_{t}\right]\right)^{\prime} \\
& =\left\{\begin{array}{l}
(I-K C) P_{t \mid t-1}\left(I-C^{\prime} K^{\prime}\right)+K D D^{\prime} K^{\prime}-K D B^{\prime} \\
-B D^{\prime} K^{\prime}+K C B D^{\prime} K^{\prime}+K D B^{\prime} C^{\prime} K^{\prime}
\end{array}\right.
\end{aligned}
$$

O ganho ótimo $K$ minimiza $P_{t \mid t}$ com a condição de primeira ordem:

$$
\frac{\partial T_{r}\left(P_{t \mid t}\right)}{\partial K}=0
$$

e solução:

$$
K=\left[P_{t \mid t-1} C^{\prime}+B D^{\prime}\right]\left[V_{y}+C B D^{\prime}+D B^{\prime} C^{\prime}\right]^{-1}
$$

Uma vez de posse da função de verossimilhança, pode-se calcular a distribuição posterior do seguinte modo:

$$
P_{t \mid t}=P_{t \mid t-1}-K_{o p t}\left[D B^{\prime}+C P_{t \mid t-1}\right]
$$

Consequentemente, as equações de atualizações serão:

$$
s_{t \mid t}=s_{t \mid t-1}+K_{o p t} \eta_{t}
$$


fechando as interações. Precisa-se aplicar esse filtro às equações de $t=1$ até $t=T$ e computar a verossimilhança.

$$
\pi\left(\theta \mid y^{T}\right)=\frac{p\left(y^{T} \mid \theta\right) \pi(\theta)}{\int p\left(y^{T} \mid \theta\right) \pi(\theta) d \theta}
$$

Para calcular essa distribuição posterior, recorre-se a um método de cadeia de markov gerada através de experimentos de Monte Carlo. Nesse método, temos um procedimento para avaliar $\pi\left(\theta \mid y^{T}\right)$ e construir uma cadeia de markov que o gera. O método para construir a cadeia de markov na estimação bayesiana é conhecido como algoritmo de Metropolis-Hastings. Nesse algoritmo, caso um valor proposto para um parâmetro aumente a posteriori, o mesmo é aceito com probabilidade 1. Caso contrário, é aceito com probabilidade menor do que 1. 